\title{
Warm Greenland during the last interglacial: the role of regional changes in sea ice cover
}

\author{
Niklaus Merz ${ }^{1,2}$, Andreas Born ${ }^{1,2}$, Christoph C. Raible ${ }^{1,2}$, and Thomas F. Stocker ${ }^{1,2}$ \\ ${ }^{1}$ Climate and Environmental Physics, University of Bern, Bern, Switzerland \\ ${ }^{2}$ Oeschger Centre for Climate Change Research, University of Bern, Bern, Switzerland \\ Correspondence to: Niklaus Merz (merz@climate.unibe.ch)
}

Received: 21 January 2016 - Published in Clim. Past Discuss.: 8 February 2016

Revised: 1 July 2016 - Accepted: 13 September 2016 - Published: 28 October 2016

\begin{abstract}
The last interglacial, also known as the Eemian, is characterized by warmer than present conditions at high latitudes. This is implied by various Eemian proxy records as well as by climate model simulations, though the models mostly underestimate the warming with respect to proxies. Simulations of Eemian surface air temperatures (SAT) in the Northern Hemisphere extratropics further show large variations between different climate models, and it has been hypothesized that this model spread relates to diverse representations of the Eemian sea ice cover. Here we use versions 3 and 4 of the Community Climate System Model (CCSM3 and CCSM4) to highlight the crucial role of sea ice and sea surface temperatures changes for the Eemian climate, in particular in the North Atlantic sector and in Greenland. A substantial reduction in sea ice cover results in an amplified atmospheric warming and thus a better agreement with Eemian proxy records. Sensitivity experiments with idealized lower boundary conditions reveal that warming over Greenland is mostly due to a sea ice retreat in the Nordic Seas. In contrast, sea ice changes in the Labrador Sea have a limited local impact. Changes in sea ice cover in either region are transferred to the overlying atmosphere through anomalous surface energy fluxes. The large-scale spread of the warming resulting from a Nordic Seas sea ice retreat is mostly explained by anomalous heat advection rather than by radiation or condensation processes. In addition, the sea ice perturbations lead to changes in the hydrological cycle. Our results consequently imply that both temperature and snow accumulation records from Greenland ice cores are sensitive to sea ice changes in the Nordic Seas but insensitive to sea ice changes in the Labrador Sea. Moreover, the simulations suggest that the uncertainty in the Eemian sea ice cover accounts for $1.6^{\circ} \mathrm{C}$ of
\end{abstract}

the Eemian warming at the NEEM ice core site. The estimated Eemian warming of $5^{\circ} \mathrm{C}$ above present day based on the NEEM $\delta^{15} \mathrm{~N}$ record can be reconstructed by the CCSM 4 model for the scenario of a substantial sea ice retreat in the Nordic Seas combined with a reduced Greenland ice sheet.

\section{Introduction}

The last interglacial (ca. 129-116 ka), also known as the Eemian, is often regarded as a possible analogue for future climate as it stands for the most recent period in the past characterized by a warmer than present-day climate. In contrast to the future year-round warming induced by rising greenhouse gas (GHG) concentrations, the Eemian warming, driven by anomalous orbital forcing, was mostly confined to the summer season and the extratropics. A warmer than present Eemian climate has been observed in various proxy records (CAPE Last Interglacial Project Members, 2006; Turney and Jones, 2010; Capron et al., 2014) and also simulated in climate model experiments (e.g., Bakker et al., 2013; Nikolova et al., 2013; Lunt et al., 2013; Merz et al., 2014a). However, model-data comparison studies have revealed rather poor agreement between simulations and data, with climate models generally underestimating the magnitude of warming inferred from proxy records (Lunt et al., 2013; Otto-Bliesner et al., 2013; Capron et al., 2014). In the Northern Hemisphere $(\mathrm{NH})$, the models indeed show a distinct warming in summer which is a direct result of increased summer insolation. In contrast, the models mostly fail to simulate a warming for winter, instead generating lower temperatures due to the decrease in winter insolation (Lunt et al., 2013). This leads to a disagreement between models and proxies in annual mean 
temperatures that either originates from missing feedbacks in the model simulations and/or misconceptions in the interpretation of the proxy records. The reasonable coherence among various Eemian proxy records (e.g., Turney and Jones, 2010; Capron et al., 2014), however, strongly suggests model deficiencies to be the major problem.

Besides the lack of agreement of climate models with proxy signals, the simulated Eemian warming can further substantially vary among different fully coupled climate models themselves, in particular in the NH mid- and high latitudes (Lunt et al., 2013; Otto-Bliesner et al., 2013; Nikolova et al., 2013). However, these studies hypothesized that model-dependent changes in sea ice are a primary cause of the diverse temperature response without testing the role of sea ice in detail. Here we will do so, as we use sea ice and sea surface temperatures (SSTs) from two different fully coupled simulations of the Eemian to force an atmospheric model. In addition, we design a set of idealized sea ice sensitivity experiments embedded in Eemian climate conditions. More precisely, we investigate the influence of sea ice changes on the temperature in and around Greenland in order to facilitate the interpretation of temperature records from Greenland ice cores. Hence, this study complements work by Merz et al. (2014a, b), who showed that changes in the Greenland ice sheet configuration can lead to distinct impacts on the local Greenland climate. Here, we make an effort to show how a reduction in NH sea ice cover can lead to a substantial warming in central Greenland, which is recorded by ice cores such as NEEM (NEEM community members, 2013), without being necessarily related to a hemisphericscale temperature anomaly.

In summary, the goals of the study are as follows: (i) quantifying the atmospheric warming in and around Greenland related to uncertainty in the Eemian sea ice cover (the uncertainty results from the spread in sea ice configurations among fully coupled models), (ii) determining whether a sea ice retreat in a particular region leads to a temperature signal recorded in Greenland ice cores such as NEEM, and (iii) understanding the key processes that link the climate in Greenland with the sea ice in adjacent areas. Note, however, that we do not aim to propose the most likely sea ice cover for the Eemian but would instead like to show the climatic consequences of one or the other scenario of sea ice coverage around Greenland.

The question of whether and to what extent the sea ice around Greenland was different during the Eemian compared to the present interglacial is difficult to answer. Firstly, no direct sea ice measurements or sea ice proxies are available for the Eemian. Furthermore, climate models simulate diverse sea ice covers for the Eemian (e.g., Otto-Bliesner et al., 2013; Nikolova et al., 2013). The latter is little surprising given the fact that there is already considerable spread among the model's representation of the NH sea ice for present-day conditions (e.g., Langehaug et al., 2013). Moreover, Eemian SST proxy records in areas adjacent to sea ice regions also show a rather complex response in the region of the North Atlantic basin: near the East Greenland coast, marine and terrestrial records indicate summer temperatures that are about $2-3{ }^{\circ} \mathrm{C}$ higher than the Holocene optimum, indicating unfavorable conditions for sea ice (Funder et al., 1998). In contrast, sediment samples from a core southeast of the Fram Strait indicate colder Nordic Seas conditions compared to the Holocene optimum (Van Nieuwenhove et al., 2011). Furthermore, the peak warming in the Nordic Seas during the Eemian is not in phase with more southerly regions of the North Atlantic, possibly due to anomalous ocean currents and delayed influx of relatively warm Atlantic water masses (Bauch et al., 2012; Born et al., 2010). For the Labrador Sea and Baffin Bay, the SST estimates presented in Capron et al. (2014) are ambiguous, but various terrestrial records from coastal Baffin Island point to temperatures clearly above present (Axford et al., 2011, and references therein), therefore suggesting a reduced Labrador Sea ice cover.

Although little is known about the precise NH sea ice extent before the modern era, the impact of sea ice on the climate of the past has been investigated with respective climate model experiments for the Greenland/North Atlantic region. A common approach is the use of sensitivity experiments where the sea ice concentration (SIC) and SSTs in the icecontaining grid cells vary among a set of simulations, with all other boundary conditions held constant. For example, Smith et al. (2003) demonstrated that there are significant changes in North Atlantic surface temperature, sea level pressure, and snowfall when changing from modern coverage to what they assume to be minimum/maximum Holocene sea ice coverage. Furthermore, Li et al. $(2005,2010)$ and Zhang et al. (2014) showed for glacial conditions that a substantial sea ice retreat in the North Atlantic results in distinct Greenland temperature and snow accumulation anomalies reflecting observed signals associated with Dansgaard-Oeschger cycles in Greenland ice cores. The majority of NH sea ice sensitivity experiments, however, have been conducted for present and future climate conditions (e.g., Alexander et al., 2004; Higgins and Cassano, 2009; Petoukhov and Semenov, 2010; Deser et al., 2010; Screen et al., 2013). These studies showed that the ongoing reduction in Arctic sea ice has a seasonally diverse impact on the local surface climate (Deser et al., 2010; Screen et al., 2013). Moreover, sea ice changes also affect the large-scale atmospheric circulation (Petoukhov and Semenov, 2010) and atmospheric modes of variability such as the North Atlantic Oscillation (Alexander et al., 2004; Kvamst $\varnothing$ et al., 2004). The atmospheric response to a sea ice retreat is further found to be sensitive to the geographical location of the ice loss (Rinke et al., 2013).

The remainder of the paper is structured as follows: Sect. 2 describes the climate model simulations, followed by Sect. 3 explaining the design of idealized "sea ice shift" experiments that simulate a sea ice retreat located either west (i.e., in the Labrador Sea/Baffin Bay) or east (i.e., in the Nordic Seas) of Greenland. In Sect. 4 we investigate existing fully coupled 
simulations of the Eemian interglacial as well as newly created atmospheric simulations that use simulated Eemian sea ice extent as prescribed lower boundary conditions. These simulations enable us to quantify the contribution of sea ice to the Eemian warming and demonstrate how differences in regional sea ice cover and SSTs can be responsible for a large part of the spread in the simulated Eemian warming found in Lunt et al. (2013) or Otto-Bliesner et al. (2013). In Sect. 5, we analyze the idealized sea ice shift experiments with a focus on changes in surface climate and their relation to the atmospheric heat and moisture budget. The results are discussed and interpreted with respect to possible consequences for Greenland ice core signals in Sect. 6 and summarized in Sect. 7.

\section{Model description and experiments}

The study is based on model simulations with versions 3 and 4 of the Community Climate System Model (CCSM) provided by the National Center for Atmospheric Research (NCAR). Both model versions include components for atmosphere, ocean, land, and sea ice, which are connected by a coupler exchanging state information and fluxes.

\subsection{CCSM3 simulations}

We use four existing fully coupled simulations generated with CCSM3 (Collins et al., 2006): (i) $\mathrm{PI}_{\text {lowRes }}$ is a preindustrial control simulation (Merkel et al., 2010) and (ii) $\mathrm{EEM}_{\text {lowRes }}$ is 30 years of output at $125 \mathrm{ka}$ from a transient (130-115 ka) orbitally accelerated Eemian simulation (Bakker et al., 2013; Govin et al., 2014; Varma et al., 2015) both using the low horizontal resolution of T31 $\left(3.75^{\circ}\right)$ in the atmosphere/land and approximately $3^{\circ}$ grid spacing in the ocean/sea ice component. Furthermore, we analyze (iii) $\mathrm{PI}_{\text {highRes }}$, a preindustrial control simulation, and (iv) $\mathrm{EEM}_{\text {highRes }}$, an Eemian simulation with perpetual $125 \mathrm{ka}$ forcing both at a resolution of T85 $\left(1.4^{\circ}\right)$ in the atmosphere/land and approximately $1^{\circ}$ in the ocean/sea ice (OttoBliesner et al., 2013). Hence, we can compute two realizations of the Eemian minus preindustrial climate anomaly (denoted as EEM-PI ${ }_{\text {lowRes }}$ and EEM-PI $I_{\text {highRes }}$ ) based on the same CCSM3 model but differing in horizontal resolution. Note that the two sets of EEM-PI realizations also used slightly different values for GHG concentrations and solar constant (Bakker et al., 2013; Otto-Bliesner et al., 2013) and that the transient character of EEM $\mathrm{EM}_{\text {lowes }}$ is different from the time-slice approach of EEM highRes. $_{\text {. }}$

\subsection{CCSM4 simulations}

Additionally, a set of simulations is generated employing CCSM4 (Gent et al., 2011) at a resolution of $0.9^{\circ} \times 1.25^{\circ}$ in the atmosphere and land surface with prescribed timevarying monthly SSTs and sea ice cover. This CCSM4 setup is termed atmosphere-land-only and comprises the Community Atmosphere Model version 4 (CAM4; Neale et al., 2010) and the Community Land Model version 4 (Oleson et al., 2010) but no dynamic representation of the ocean and sea ice. Besides the benefit of being computationally costefficient compared to fully coupled simulations, this setup is convenient for sea ice sensitivity experiments, as one can simply compute the atmospheric response to any prescribed change in sea ice (and SSTs). As a drawback, these simulations do not allow feedbacks with the ocean and sea ice components. A general model validation of the CCSM4 atmosphere-land-only setup is given by Evans et al. (2013).

In total, we perform 12 simulations with CCSM4, of which the 6 simulations listed in Table 1 build the core of this study, whereas the remainder of the simulations will be shortly discussed in Sect. 5.4. Each simulation has a length of 30 years plus a 3-year spin-up phase, and the external forcing is held constant throughout the simulation.

\subsubsection{Eemian and preindustrial experiments with prescribed SSTs/sea ice}

The first set of CCSM4 experiments consists of two preindustrial simulations with AD 1850 external forcing and two Eemian simulations with $125 \mathrm{ka}$ external forcing. The Eemian external forcing differs from preindustrial conditions by lower GHG concentrations (Table 1) and anomalous solar insolation due to differences in the orbital parameters. The climate effect simulated by CCSM4 associated with these changes in external forcing is described in Merz et al. (2014a, b).

The atmosphere-land-only setup further requires appropriate SST and sea ice fields as input data. We use the output of the respective fully coupled CCSM3 simulations mentioned above: the CCSM4 simulations $\mathrm{PI}_{1}$ and $\mathrm{EEM}_{1}$ use output of the preindustrial and Eemian simulations generated with the (lowRes) $\mathrm{T} 31 \times 3^{\circ} \mathrm{CCSM} 3$, whereas $\mathrm{PI}_{2}$ and $\mathrm{EEM}_{2}$ use output of the (highRes) T85 $\times 1^{\circ} \mathrm{CCSM} 3$. Note that the CCSM4 simulations themselves all use the same horizontal resolution of $0.9^{\circ} \times 1.25^{\circ}$.

With the two pairs of PI and EEM atmosphere-land-only CCSM4 simulations we create equivalents to the existing fully coupled CCSM3 simulations. Hence, we can compute two realizations of the EEM-PI climate anomaly (denoted as EEM-PI 1 and EEM-PI 2 ) based on the exact same CCSM4 model and external forcing but differing in terms of prescribed SSTs and sea ice. Consequently, this setup eliminates uncertainties arising from different model physics and parameterizations at different resolutions (as is the case in the fully coupled CCSM3 simulations). This enables a more robust analysis of the impact of sea ice and SSTs. 
Table 1. List of the core CCSM4 model experiments. Present-day levels are denoted as pd and Eemian (125 ka) as eem. The orbital parameters are calculated according to Berger (1978). SST and sea ice fields are output of respective fully coupled CCSM3 simulations described in Sect. 2.1. GHG concentrations are fixed at the attributed level and correspond to Varma et al. (2015). Solar forcing, vegetation, and ice sheets are held constant at the preindustrial level in all simulations.

\begin{tabular}{|c|c|c|c|c|c|}
\hline Simulation & $\begin{array}{l}\text { Orbital } \\
\text { parameters }\end{array}$ & $\begin{array}{l}\mathrm{SST} / \\
\text { sea ice }\end{array}$ & $\begin{array}{c}\mathrm{CO}_{2} \\
(\mathrm{ppm})\end{array}$ & $\begin{array}{l}\mathrm{CH}_{4} \\
(\mathrm{ppb})\end{array}$ & $\begin{array}{l}\mathrm{N}_{2} \mathrm{O} \\
(\mathrm{ppb})\end{array}$ \\
\hline \multicolumn{6}{|c|}{ Preindustrial } \\
\hline $\mathrm{PI}_{1}$ & $\mathrm{pd}$ & $\mathrm{PI}_{\text {lowRes }}\left(3^{\circ}\right)$ & 280 & 760 & 270 \\
\hline $\mathrm{PI}_{2}$ & $\mathrm{pd}$ & $\mathrm{PI}_{\text {highRes }}\left(1^{\circ}\right)$ & 280 & 760 & 270 \\
\hline \multicolumn{6}{|l|}{ Eemian } \\
\hline $\mathrm{EEM}_{1}$ & eem & $\mathrm{EEM}_{\text {lowRes }}\left(3^{\circ}\right)$ & 272 & 622 & 259 \\
\hline $\mathrm{EEM}_{2}$ & eem & $\operatorname{EEM}_{\text {highRes }}\left(1^{\circ}\right)$ & 272 & 622 & 259 \\
\hline $\mathrm{EEM}_{\mathrm{LabS}}$ & eem & LabS-shift & 272 & 622 & 259 \\
\hline EEM $_{\text {NordS }}$ & eem & NordS-shift & 272 & 622 & 259 \\
\hline
\end{tabular}

\subsubsection{Sea ice sensitivity experiments}

A second set of CCSM4 experiments is designed to analyze the atmospheric response to an idealized sea ice retreat in a specific geographical area. As will be shown in Sect. 4, both the Labrador Sea/Baffin Bay (LabS) and the Nordic Seas (NordS) region are reasonable candidates for a distinct Eemian warming induced by a local sea ice reduction. In order to evaluate the importance of these two areas separately, we design both the scenario of a sea ice retreat in the LabS area (simulation denoted as $\mathrm{EEM}_{\mathrm{LabS}}$ ) and a sea ice retreat in

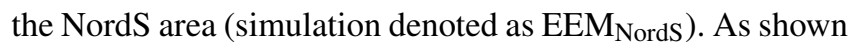
in Table 1, EEM $\mathrm{LabS}_{\text {and }} \mathrm{EEM}_{\mathrm{NordS}}$ are identical to $\mathrm{EEM}_{1}$ with the exception of the modified sea ice and SSTs used at the lower boundary and are thus classical sea ice sensitivity experiments embedded in an Eemian background climate.

\subsection{Model validation and definition of climate anomalies}

Both models, CCSM3 and CCSM4, are widely used in the climate science community and have been thoroughly validated for present-day climate conditions (e.g., Collins et al., 2006; Yeager et al., 2006; Gent et al., 2011; Evans et al., 2013). When comparing the high- and low-resolution versions of CCSM3, the latter is generally found to have a stronger cold bias in the North Atlantic related to underestimated ocean heat transport and excessive Arctic sea ice (Yeager et al., 2006). However, Lunt et al. (2013) illustrate (their Fig. 4) that indeed both model versions rather underestimate SATs in the North Atlantic sector for preindustrial conditions. In the successor model, CCSM4, these biases have been substantially improved through changes in sea ice albedo and ocean overflow parameterizations (Gent et al., 2011). Further, CCSM4 shows in general good skill in simulating the present-day surface climate and atmospheric circulation in and around Greenland (Vizcaino et al., 2013; Merz et al., 2013, 2014b). Hence, we have good confidence in CCSM4's capability in representing the components of the North Atlantic and Greenland climate system that are of importance for this study, e.g., SAT, surface energy fluxes, surface winds, or precipitation.

The CCSM3 has further been used for a number of simulations of the Eemian interglacial and respective comparisons with Eemian proxy records (e.g., Lunt et al., 2013; Otto-Bliesner et al., 2013; Capron et al., 2014). Rather than looking at absolute Eemian climate conditions, we compare models and proxies based on their EEM-PI climate anomaly. Comparing the change in Eemian climate with preindustrial values avoids possible caveats associated with mean climate model biases and the calibration of proxies to an absolute level. Equivalently, we focus in this study on the simulated EEM-PI climate anomaly to quantify the Eemian state of any target climate variable. More precisely, we define a set of climate anomalies listed in Table 2. Based on the CCSM3 simulations we compute EEM-PI $\mathrm{I}_{\text {lowRes }}$ and EEM-PI highRes $_{\text {differing in horizontal resolution as well as }}$ other minor settings as explained in Sect. 2.1. Similarly, we calculate EEM-PI 1 and EEM-PI ${ }_{2}$, which are based on the same atmosphere-land-only CCSM4 setup but differ with respect to the origin of the prescribed lower boundaries (either $\mathrm{CCSM} 3_{\text {lowRes }}$ or $\mathrm{CCSM} 3_{\text {highRes }}$ ). The difference between these two last EEM-PI anomalies themselves is referred to

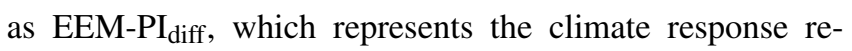
lated to the spread/uncertainty in the EEM-PI sea ice and SST changes. In addition, we use the terms "LabS-shift" and "NordS-shift" for the comparison of the EEM experiments including a regional shift in lower boundary conditions compared to the reference experiment (i.e., the situation before the sea ice shift). 
Table 2. Definitions of climate anomalies used throughout the paper. Please refer to Sects. 2.1 and 2.2 for details on individual simulations.

\begin{tabular}{|c|c|c|}
\hline Abbreviation & Calculation & Description \\
\hline EEM-PI lowRes & $\mathrm{EEM}_{\text {lowRes }}-\mathrm{PI}_{\text {lowRes }}$ & $\begin{array}{l}\text { Eemian minus preindustrial climate anomaly based on simulations } \\
\text { with the low-resolution }\left(3^{\circ}\right) \mathrm{CCSM} 3\end{array}$ \\
\hline EEM-PI $_{\text {highRes }}$ & $\mathrm{EEM}_{\text {highRes }}-\mathrm{PI}_{\text {highRes }}$ & $\begin{array}{l}\text { Eemian minus preindustrial climate anomaly based on simulations } \\
\text { with the high-resolution }\left(1^{\circ}\right) \text { CCSM } 3\end{array}$ \\
\hline $\mathrm{EEM}^{-\mathrm{PI}_{1}}$ & $\mathrm{EEM}_{1}-\mathrm{PI}_{1}$ & $\begin{array}{l}\text { Eemian minus preindustrial climate anomaly based on CCSM4 simulations } \\
\text { prescribing SSTs and sea ice from the low-resolution }\left(3^{\circ}\right) \text { CCSM3 }\end{array}$ \\
\hline $\mathrm{EEM}^{-\mathrm{PI}_{2}}$ & $\mathrm{EEM}_{2}-\mathrm{PI}_{2}$ & $\begin{array}{l}\text { Eemian minus preindustrial climate anomaly based on CCSM4 simulations } \\
\text { prescribing SSTs and sea ice from the high-resolution }\left(1^{\circ}\right) \text { CCSM3 }\end{array}$ \\
\hline EEM-PI $_{\text {diff }}$ & $\begin{array}{l}\text { EEM-PI } 2-E E M-P I_{1} \\
=\left(\mathrm{EEM}_{2}-\mathrm{PI}_{2}\right)-\left(\mathrm{EEM}_{1}-\mathrm{PI}_{1}\right)\end{array}$ & $\begin{array}{l}\text { Difference in Eemian minus preindustrial climate anomaly in CCSM4 } \\
\text { due to different (high- vs. low-resolution) SSTs and sea ice }\end{array}$ \\
\hline LabS-shift & $\mathrm{EEM}_{\mathrm{LabS}}-\mathrm{EEM}_{1}$ & Climate anomaly due to idealized Labrador Sea shift in CCSM4 \\
\hline NordS-shift & $\mathrm{EEM}_{\text {NordS}}-\mathrm{EEM}_{1}$ & Climate anomaly due to idealized Nordic Seas shift in CCSM4 \\
\hline
\end{tabular}

\section{A new type of idealized sea ice sensitivity experiment}

Various types of sea ice reduction experiments have been presented in previous studies: a prominent approach is to implement an observed or simulated minimum sea ice cover (e.g., Smith et al., 2003; Alexander et al., 2004) or an altered sea ice climatology that exhibits a retreated sea ice cover compared to its reference (e.g., Higgins and Cassano, 2009; Deser et al., 2010). An alternative option is to artificially reduce the SIC in a target region to a certain percentage (e.g., Petoukhov and Semenov, 2010). What these experimental designs have in common is that they use a repeating seasonal cycle of SICs (and SSTs) and thus are not accounting for interannual variability. The absence of interannual variability in the ocean/sea ice representation, however, can be a drawback with respect to atmospheric dynamics, e.g., causing a storm track in the North Atlantic that is too zonally oriented (Raible and Blender, 2004).

To avoid this deficiency and also to be consistent with the preindustrial and Eemian CCSM4 simulations, which use time-varying SSTs and sea ice (including interannual variability), the "sea ice shift" approach is applied (illustrated in Fig. 1). We take the monthly varying lower boundary conditions previously used for CCSM4 EEM 1 and modify the values in the target region by shifting them along a certain axis. For the $\mathrm{EEM}_{\mathrm{LabS}}$ simulation we shift all SIC values in the LabS domain northwestward (see Fig. 1a). In technical terms, all values within the solid green box in Fig. 1a are replaced point by point by the values within the dashed box. Values in the green-shaded area are linearly interpolated to guarantee a smooth transition with the adjacent regions. Similarly, for $\mathrm{EEM}_{\mathrm{NordS}}$ we shift all SIC values in the NordS domain (dashed green box in Fig. 1b) northwards. As illustrated by the $50 \%$ sea ice contour lines in Fig. 1a and b, this approach results in a local sea ice retreat in the perturbed experiment (dashed contour) compared to the reference simulation (solid contour). Note that in all cases we only change the sea ice area, while the sea ice thickness is fixed at $2 \mathrm{~m}$ throughout the Arctic, which is the default for CCSM4 simulations with prescribed lower boundary conditions.

A key consideration in all types of sea ice sensitivity experiments is the prescription of corresponding SST changes. For example, grid cells becoming ice-free are exposed to solar radiation and thus local SSTs likely increase compared to the typical freezing point temperature of $-1.8^{\circ} \mathrm{C}$ of an ocean grid cell completely covered by ice. Conversely, the sea ice retreat itself can be caused by a warming of the surface ocean, and hence a reduction in SIC is usually accompanied by an increase in SSTs. This strong relationship between SST and SIC in marginal sea ice areas is also found in the input data used for $\mathrm{EEM}_{1}$ (dashed lines in Fig. 1c, d) along the transects $\mathrm{A} \rightarrow \mathrm{B}$ and $\mathrm{C} \rightarrow \mathrm{D}$ in the two target regions. In order to account for this strong link between the sea ice cover and SSTs, we shift the SSTs in the same way as the SICs (see solid lines in Fig. 1c, d). This approach seems particularly reasonable for the LabS region, where we find gradual changes along the transect (Fig. 1c). Hence, the northwestward LabS-shift in EEM $_{\text {LabS }}$ can be understood as a warm water inflow into the LabS area (see SSTs in LabS in Fig. 1a compared to Fig. 1b), resulting in a coherent sea ice retreat. In contrast, the situation in the Nordic Seas is more complex (Fig. 1d) as the northward shift in SSTs corresponds to a displacement of local ocean currents with a nonparallel orientation to the $\mathrm{C} \rightarrow \mathrm{D}$ axis along which we apply the shift. For example, the northward NordS-shift results in a removal of

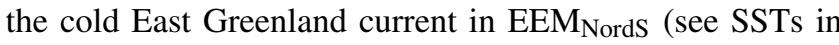
NordS in Fig. 1b compared to a).

Additionally, we generate a second pair of LabSand NordS-shift experiments (termed EEM LabS ICE $_{\text {and }}$ $\mathrm{EEM}_{\text {NordS ICE }}$ ) for which we only shift the SICs (equivalently to $\mathrm{EEM}_{\mathrm{LabS}}$ and $\mathrm{EEM}_{\text {NordS }}$ ) and not the SSTs. Hence, this second approach avoids a possibly unrealistic warming of the surface ocean but, on the other hand, violates the obvious SST-SIC relationship revealed in Fig. 1c and d. Thus, EEM $_{\text {LabS ICE }}$ and EEM $_{\text {NordS ICE }}$ can be understood as exper- 

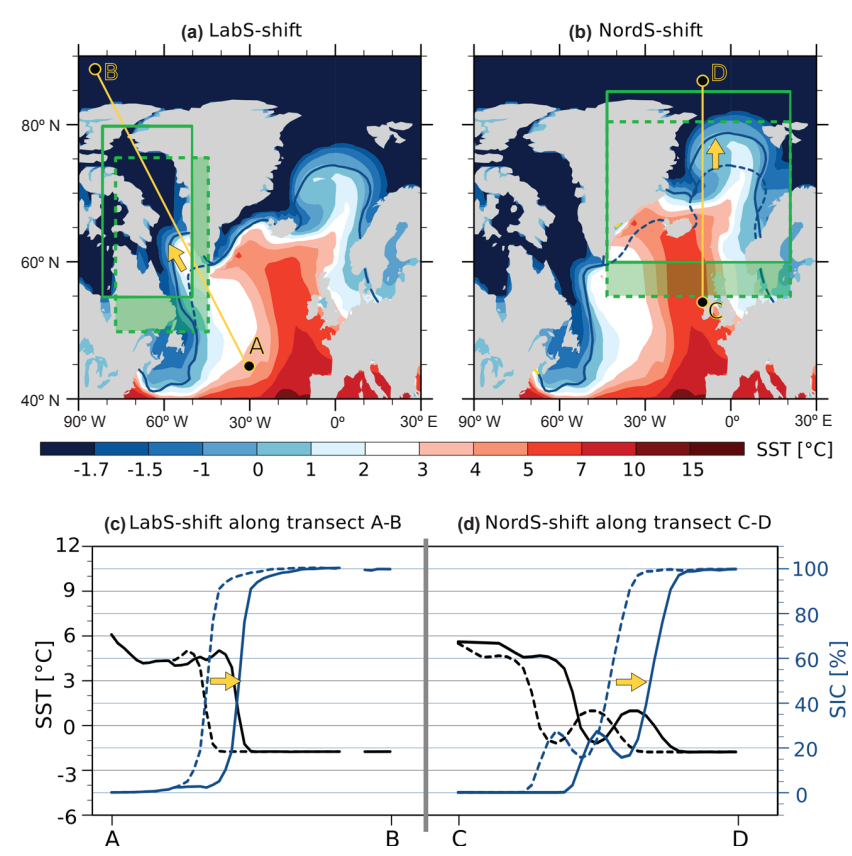

Figure 1. Illustration of sea ice shift experiments (shown for mean winter conditions) in two areas around Greenland enclosed in green boxes: (a) Labrador Sea shift in sea surface temperature (SST, shaded) and sea ice concentration (SIC, $50 \%$ solid contour) in

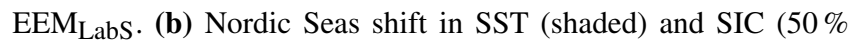
solid contour) in EEM $_{\text {NordS }}$. The dashed contours in (a) and (b) denote the $50 \%$ SIC isoline before the shift (i.e., in $\mathrm{EEM}_{1}$ ). In technical terms, the shift means that sea ice and SST values within the solid green boxes are replaced point by point by the values within the dashed green boxes. Values in the green-shaded area are linearly interpolated to guarantee a smooth transition with the adjacent regions. The consequences of the shift experiments for SST and SIC values are further illustrated in (c) for a transect through the Labrador Sea $(\mathrm{A} \rightarrow \mathrm{B})$ and in $(d)$ for a transect through the Nordic Seas $(C \rightarrow D)$. Dashed lines in $(\mathbf{c})$ and $(\mathbf{d})$ denote values before the shift (e.g., the reference simulation EEM $_{1}$ ), whereas solid lines indicate values after the shift (e.g., $E M_{\text {LabS }}$ or $E E M_{\text {NordS }}$ ).

iments providing the lower range in terms of atmospheric response to a prescribed sea ice retreat. A detailed discussion of the atmospheric response to different experimental designs is presented in Sect. 5.4.

In summary, our sea ice shift experiments are of idealized nature but the SIC and SST boundary conditions locally resemble fields from the fully coupled CCSM3 simulations. The direction and magnitude of the shift are chosen to locally, i.e., either in the Labrador Sea or the Nordic Seas, mimic the difference between CCSM3 $3_{\text {lowRes }}$ and CCSM3 $3_{\text {highRes }}$ in order to disentangle their combined ef-

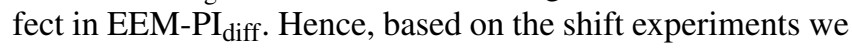
can further assess the climate response related to the uncertainty in the EEM-PI sea ice and SST changes resulting from the spread among the fully coupled models.

\section{Simulated Eemian warming: importance of sea ice and SSTs}

\subsection{Atmospheric temperature response in fully coupled CCSM3 simulations}

The first part of our analysis assesses the uncertainty of the Eemian warming as suggested by the spread among state-of-the-art climate models. This relates to the modelintercomparison study by Lunt et al. (2013), which showed that the EEM-PI annual mean atmospheric warming (their Fig. 5) strongly varies among different models and even applies to two EEM-PI simulations with the same climate model but different model versions (denoted as CCSM3_Bremen and CCSM3_NCAR therein). Here we show an analogous comparison of the EEM-PI temperature response of two versions (EEM-PI ${ }_{\text {highRes }}$, Fig. 2a) and EEM$\mathrm{PI}_{\text {lowRes }}$, Fig. 2c) of fully coupled CCSM3 simulations.

CCSM3 EEM-PI $I_{\text {highRes }}$ exhibits a distinct warming in the $\mathrm{NH}$ high latitudes, with the strongest signal occurring in an area including the Arctic, Greenland, and the North Atlantic (Fig. 2a). Significant warming but of smaller magnitude is further found in Europe and most of North America. In con-

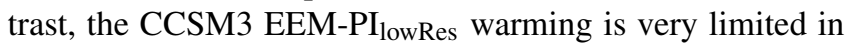
terms of magnitude and spatial expansion (Fig. 2c). In fact, large areas of the $\mathrm{NH}$ experience an annual mean cooling. The difference between the two EEM-PI warming patterns (Fig. 2e) illustrates a stronger warming of EEM-PI $\mathrm{I}_{\text {highes }}$

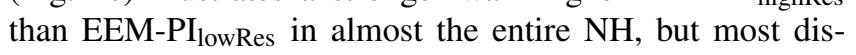
tinctively over the Arctic and the North Atlantic ocean.

The main reason for the remarkable discrepancy in EEMPI warming among the two pairs of CCSM3 simulations is likely the different horizontal resolution as it has been shown that the low- and high-resolution versions of CCSM3 show distinct differences for various climatic features even under present-day conditions (Yeager et al., 2006). Moreover, the two sets of simulations do not include identical GHG and solar forcing for either the PI (Otto-Bliesner et al., 2013; Merkel et al., 2010) or the EEM simulations (Otto-Bliesner et al., 2013; Bakker et al., 2013): CCSM3 EEM highRes $_{\text {in- }}$ cludes a slight increase in the solar constant and the $\mathrm{N}_{2} \mathrm{O}$

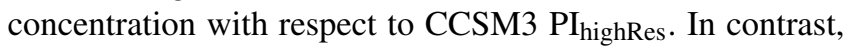
CCSM3 $\mathrm{EEM}_{\text {lowRes }}$ uses the same solar constant but consistently lower GHG concentrations than CCSM3 PI lowRes. Hence, slight differences in the prescribed external forcing may also contribute to the spread in the EEM-PI warming pattern, here as well as in Lunt et al. (2013).

\subsection{Atmospheric temperature response in CCSM4 simulations with prescribed sea ice and SSTs}

In the next step, we aim to link the discrepancy in EEMPI temperature response among the two CCSM3 versions (discussed in Sect. 4.1) with the models' representation of SSTs and sea ice in the North Atlantic sector. For consis- 

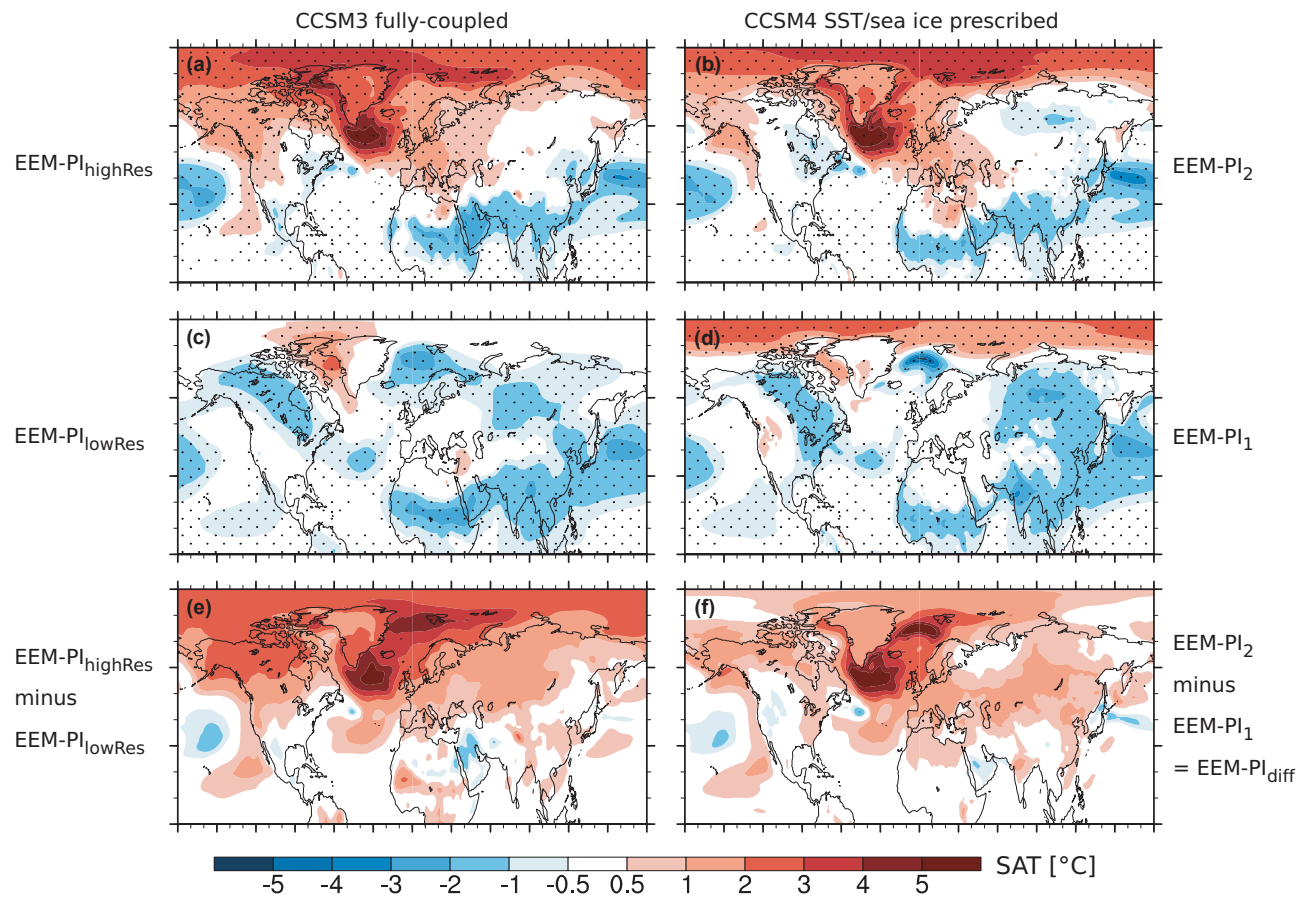

Figure 2. Eemian minus preindustrial (EEM-PI) annual mean surface air temperature (SAT) change in (a) EEM-PI $\mathrm{HighRes}$, (b) EEM-PI ${ }_{2}$, (c) EEM-PI lowRes $_{\text {and (d) EEM-PI }}$. Note that (a) and (c) are based on the fully coupled CCSM3, whereas (b), and (d) are based on the atmosphere-land-only CCSM4 with prescribed sea surface temperature (SST) and sea ice from the corresponding CCSM3 simulations, i.e.,

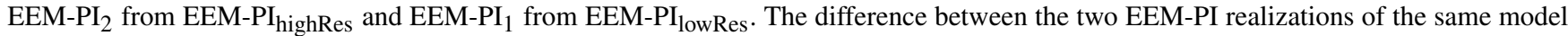
is shown in (e) for the fully coupled CCSM3 and in (f) for the atmosphere-land-only CCSM4. Stippling in (a)-(d) denotes EEM-PI changes significant at the $5 \%$ level based on $t$ test statistics applied to respective annual mean SAT time series.

tency this evaluation is done with one single model (i.e., the atmosphere-land-only CCSM4) using the SSTs and sea ice of both preindustrial and both Eemian fully coupled CCSM3 simulations as boundary conditions (see Sect. 2.2 for details on the model setup).

Comparing the CCSM4 simulations with their CCSM3 equivalents, we find high similarity: the CCSM4 EEM-PI 2 (Fig. 2b) largely exhibits the same distinct high-latitude

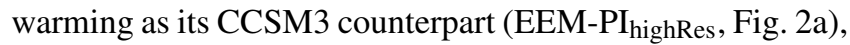
and there is also high agreement for EEM-PI ${ }_{1}$ and EEM$\mathrm{PI}_{\text {lowRes }}$ (Fig. 2c and d). Eventually, the CCSM4 EEM-PI ${ }_{\text {diff }}$ SAT pattern (Fig. 2f) strongly suggests that large parts of the spread between the two diverse fully coupled CCSM3 EEMPI responses (shown in Fig. 2e) originate from differences in SSTs and sea ice. Note that the two pairs of CCSM4 simulations (i.e., $\mathrm{PI}_{1}, \mathrm{PI}_{2}$ and $\mathrm{EEM}_{1}, \mathrm{EEM}_{2}$ ) use identical experimental setups (see Table 1), so the CCSM4 EEM-PI diff $_{\text {pat- }}$ tern (Fig. 2f) necessarily results from differences in the prescribed SSTs and sea ice. The strongest impact of the lower boundary conditions is simulated for the area around Greenland, but the warming extends throughout most of the $\mathrm{NH}$ extratropics. In contrast, the influence of the lower boundary conditions on low-latitude regions is smaller in magnitude. In the following we will focus on the distinct EEM-PI $\mathrm{d}_{\text {diff }} \mathrm{SAT}$ signal in the Greenland/North Atlantic region and analyze in detail its relationship with the underlying sea ice cover and SSTs.

The EEM-PI change in SSTs and sea ice simulated by the two fully coupled CCSM3 simulations is shown in Fig. 3. EEM-PI $I_{\text {highRes }}$ shows a warming of the North Atlantic and a retreat of the sea ice cover in all seasons. In winter (DJF) and spring (MAM), the main reduction in sea ice is confined to the Labrador Sea, whereas in summer and autumn the sea ice cover in the Nordic Seas is reduced as well. The strongest increase in SSTs ( $>4{ }^{\circ} \mathrm{C}$ anomaly) is found south of Greenland, corresponding to a strengthening of the Atlantic subpolar gyre that fosters convection of relatively warm subsurface water. A strong subpolar gyre during the Eemian induced by decreased sea ice export from the Arctic is in agreement with previously published results based on two different climate models and marine sediment proxies (Born et al., 2010, 2011).

The EEM-PI $\mathrm{I}_{\text {lowRes }}$ change in SSTs and sea ice (Fig. 3, bottom row) deviates from EEM-PI ${ }_{\text {highRes. }}$ In fact, the North Atlantic mostly cools and even the high levels of summer insolation during the Eemian only result in a moderate surface warming in shallow coastal waters. In the Nordic Seas, the summer SSTs even decrease and the sea ice cover is expanded during the Eemian compared to the preindustrial climate throughout the year. This likely relates to a relatively 

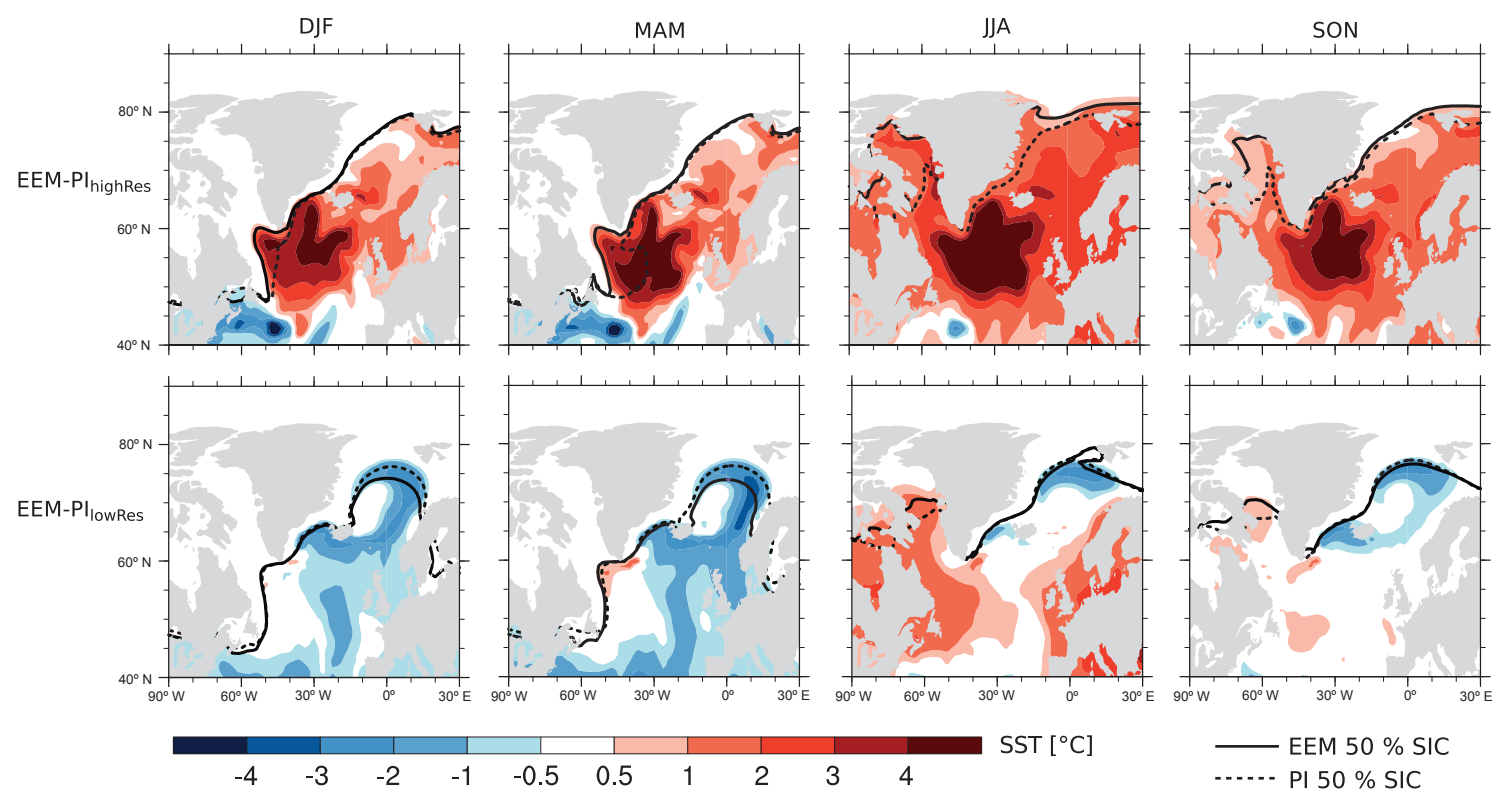

Figure 3. CCSM3 Eemian minus preindustrial (EEM-PI) seasonal mean sea surface temperature change (SST, shaded) and EEM (solid) vs. PI (dashed) $50 \%$ sea ice concentration (SIC) contours. The top row is based on the high-resolution $\left(1^{\circ}\right)$ simulations and the bottom row on the low-resolution $\left(3^{\circ}\right)$ simulations. Note that these SST/SIC fields are used as lower boundary conditions for the atmosphere-land-only CCSM4 simulations.

weak Atlantic meridional overturning circulation (AMOC) in low resolution during the Eemian (Bakker et al., 2013) compared to present day (Yeager et al., 2006).

The diverging oceanic responses among the two versions of the fully coupled CCSM3 to the Eemian external forcing are likely connected to intermodel differences in the mean ocean state for present-day conditions and hence linked to the model biases. Note that, for present day, the low-resolution CCSM3 already exhibits too weak an AMOC and, consequently, an underestimated heat transport to the North Atlantic that fosters a large sea ice cover (Yeager et al., 2006). In the present-day high-resolution CCSM3, the AMOC is stronger and the $\mathrm{NH}$ sea ice cover is smaller, which is closer to observations. However, the high-resolution CCSM3 still has a pronounced cold bias in the subpolar North Atlantic (Collins et al., 2006) related to an underestimated subpolar gyre, which itself is a consequence of biases in the surface wind forcing (Large and Danabasoglu, 2006). As described above, the subpolar gyre seems to strengthen for Eemian climate conditions in the high-resolution CCSM3, causing warmer SSTs and a reduced sea ice cover in many areas of the North Atlantic (Fig. 3, top row). In contrast, the overestimation of the NH sea ice in the low-resolution CCSM3 likely generates North Atlantic conditions that prevent an Eemian strengthening of the subpolar gyre due to the non-linear character of the gyre dynamics and its strong dependence on the background salinity and thus freshwater fluxes linked to sea ice processes (Born and Stocker, 2014). Consequently, we are missing a respective warming of the North Atlantic in

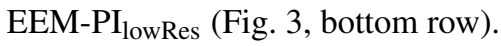

When using these CCSM3 sea ice and SSTs as prescribed lower boundary conditions for the CCSM4 atmosphere-landonly simulations, the distinct differences in the EEM-PI changes in terms of lower boundary conditions directly translate into respective responses in the CCSM4 atmospheric temperature (compare Figs. 3 and 4). As expected, the influence of sea ice and SSTs is particularly strong on SATs above oceanic grid cells; for instance, any EEM-PI cooling or warming in SSTs can be identified in the EEM-PI SAT response. For example, in Eemian winters the decreased solar insolation leads to a widespread atmospheric cooling, but in EEM-PI 2 (Fig. 4, top left) the direct effect of the external forcing on SATs is superimposed on the North Atlantic domain by oceanic changes showing a warming (Fig. 3, top left). Consequently, we find clear differences between the EEM-PI ${ }_{1}$ and EEM-PI $\mathrm{I}_{2}$ warming in both annual mean (Fig. 2) and seasonal mean (Fig. 4) SATs. The strongest seasonal differences in SATs as a result of diverging lower boundary conditions is found for DJF and MAM (see Fig. 4, bottom row). In these two seasons, the EEM-PI diff warming is not restricted to oceanic areas but also includes substantial changes in Greenland's SATs. In contrast, the differences in lower boundary conditions scarcely lead to a diverse warming outside of the North Atlantic domain during summer.

In summary, we have demonstrated that distinct differences in the simulated Eemian warming based on fully coupled models are explained by their differences in sea ice and 


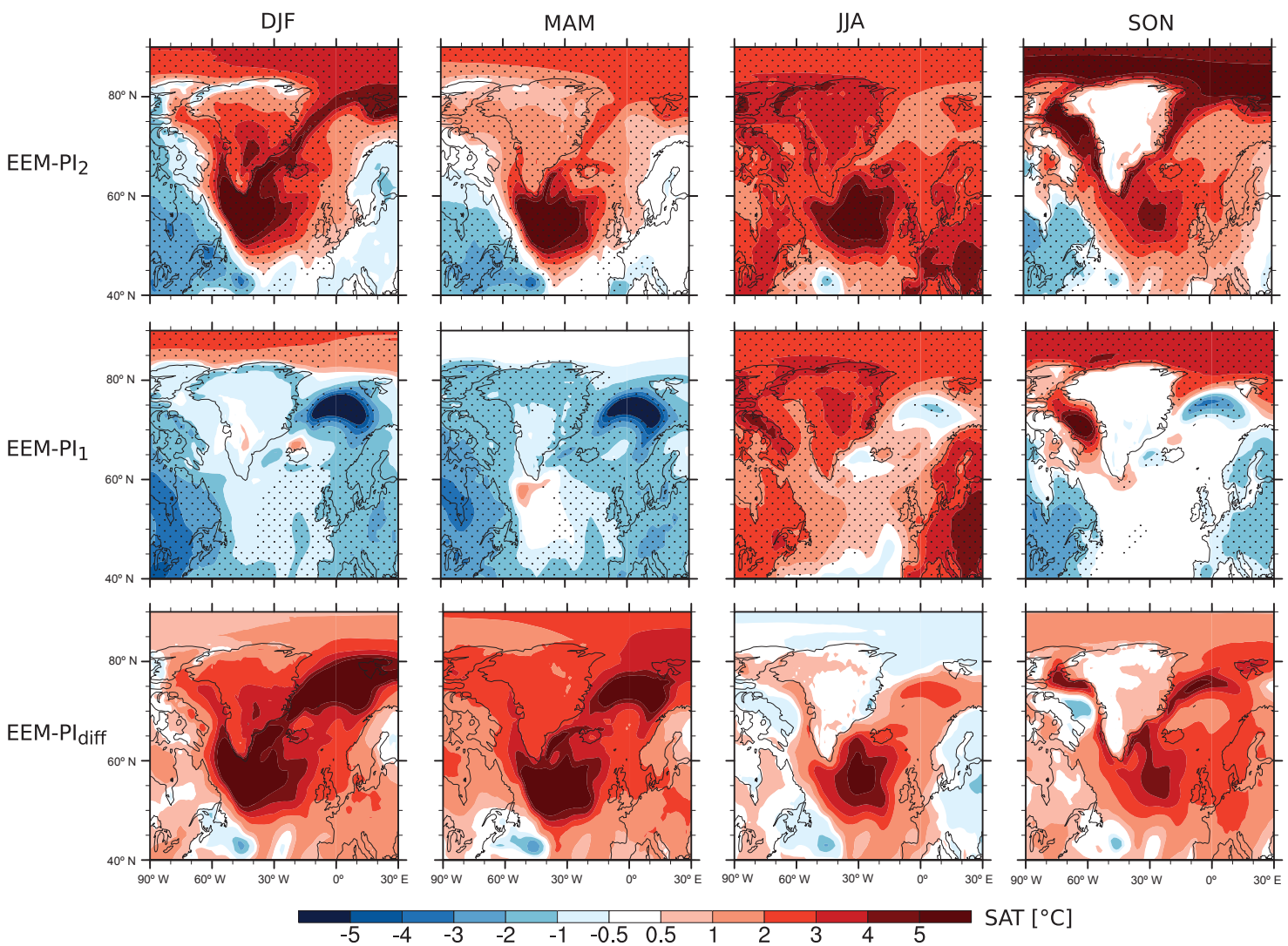

Figure 4. CCSM4 Eemian minus preindustrial (EEM-PI) seasonal mean surface air temperature (SAT) change. The top row shows the result for EEM-PI 2 , the middle row the result for EEM-PI 1 , and the bottom row the result their differences (EEM-PI diff $_{\text {. }}$. Stippling in the top and middle row denotes EEM-PI changes significant at the $5 \%$ level based on $t$ test statistics.

SSTs. The influence of the sea ice cover and the surface ocean on the EEM-PI atmospheric response is particularly strong in the North Atlantic and apparent in all four seasons but especially in winter. In the following, we focus on winter and analyze the processes that are responsible to transmit changes in sea ice/SSTs to the atmosphere. Furthermore, we study atmospheric transport processes which control how the available heat in the atmosphere is spatially distributed. Eventually, the seasonality of key processes is presented in Sect. 5.3.

\subsection{Oceanic heat sources}

The distinct EEM-PI diff $_{\text {warming (Fig. 4, bottom row) needs }}$ to be understood as an additional Eemian warming caused by the prescribed CCSM $33_{\text {highRes }}$ SSTs and sea ice with respect to the CCSM3 $3_{\text {lowRes }}$ boundary conditions. This effect is unrelated to the direct atmospheric response to the Eemian external forcing. Consequently, the EEM-PI diff $_{\text {warming re- }}$ quires oceanic heat sources, i.e., an increased heat transfer from the surface ocean to the atmosphere. Two types of heat sources are possible: either a warmer surface ocean, which directly warms the overlying atmosphere, or a reduction in the sea ice cover, which exposes a relatively cold atmosphere to the underlying (warmer) ocean surface. In order to assess these two processes for winter, we compare the DJF EEM$\mathrm{PI}_{\text {diff }}$ SST and SIC anomalies with the response of the atmospheric surface energy fluxes (Fig. 5). All surface energy fluxes are defined positive in the upward direction - i.e., a positive flux is warming the overlying atmosphere.

The comparison of the SST/SIC map (Fig. 5a) with the net surface energy flux response (Qnet, Fig. 5b) reveals that most of the warmer North Atlantic acts as a heat source. Qnet is defined here as the sum of sensible heat, latent heat and longwave radiation. We omit the shortwave component in the calculation of Qnet because increased downward shortwave radiation resulting from modifications in surface albedo, e.g., by changing an ocean grid cell from ice-covered to ice-free, does not warm the atmosphere directly but warms the ocean, an effect that is suppressed in our experimental setup, where SSTs are prescribed.

The strongest positive Qnet anomaly is confined to the areas of sea ice retreat in the Labrador Sea, the East Greenland Current south of Denmark Strait, and the northern Nordic Seas. The dominant components of Qnet are the turbulent energy fluxes (sensible and latent heat, Fig. 5c, d), which 
(a) SST $\left({ }^{\circ} \mathrm{C}\right)$ and $\mathrm{SIC}(\%)$

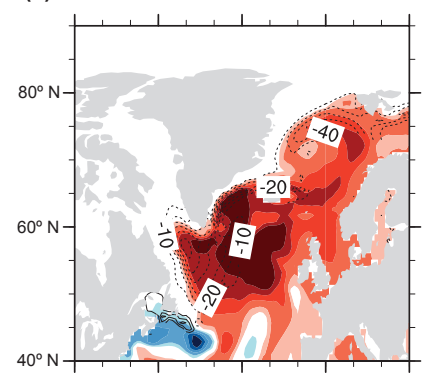

(c) $\mathrm{SHF}\left(\mathrm{W} \mathrm{m}^{-2}\right)$

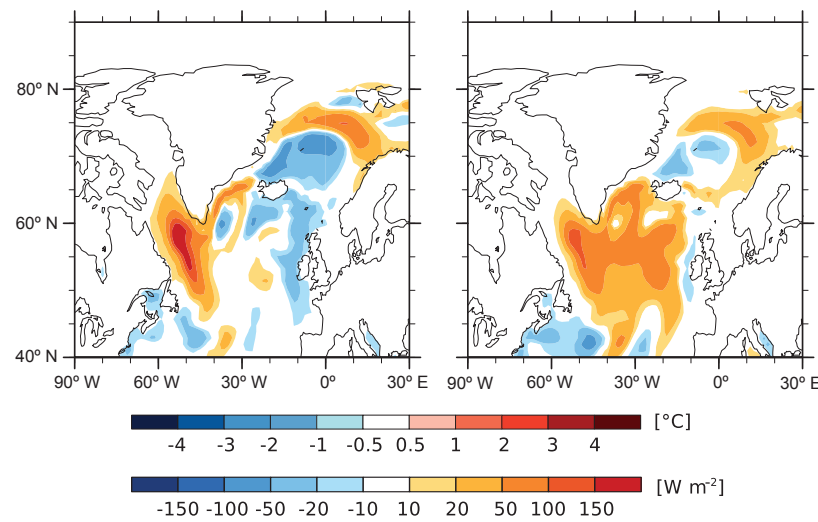

Figure 5. CCSM4 EEM-PI ${ }_{\text {diff }}$ response in winter (DJF) mean (a) sea surface temperature (SST, shaded) and sea ice concentration (SIC, contours), (b) net surface energy flux (Qnet), (c) sensible heat flux (SHF), and (d) latent heat flux (LHF). Negative sea ice anomalies in (a) are dashed and the contour interval is $10 \%$. Energy fluxes are positive upward.

show an increase of up to $150 \mathrm{~W} \mathrm{~m}^{-2}$. In contrast, the radiative fluxes (10-20 $\mathrm{W} \mathrm{m}^{-2}$ increase) are of second-order importance. This result is in agreement with previous sea ice sensitivity experiments (e.g., Deser et al., 2010). In fact, the DJF net longwave radiation slightly increases over the warming North Atlantic (not shown), whereas shortwave radiation is mostly absent in the high-latitude $\mathrm{NH}$ during winter. The turbulent energy fluxes (Fig. 5c, d) show negative responses in areas adjacent to sea ice loss and therefore adjacent to the regions with the strongest positive energy flux responses. The resulting dipole patterns can be understood by considering that the positive fluxes locally warm the low-level atmosphere, and this heat can be transported to areas nearby. The warmer air masses then lose some of their excess heat to the underlying ocean, resulting in negative heat fluxes. Hence, the SSTs would rise in regions with negative flux responses, and eventually this would dampen the negative fluxes by reducing the air-ocean temperature difference. However, as SSTs are prescribed in our CCSM4 simulations, this negative feedback is suppressed and consequently the dipoles in turbulent energy flux responses are rather pronounced. Nevertheless, similar dipole features were also identified in fully coupled model simulations (Deser et al., 2010) as well as in atmospheric reanalyses (Screen and Simmonds, 2010) and thus are only partly due to our experimental setup.

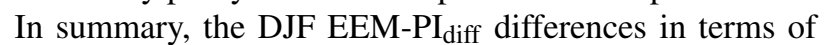
SSTs and SICs lead to several distinct oceanic heat source areas in the North Atlantic, whereof the areas marked by a sea ice retreat are strongest, as indicated by the maximum in (upward) surface energy flux anomalies (Fig. 5b-d).

\section{Atmospheric response to sea ice retreat in Labrador Sea vs. Nordic Seas}

Section 4 has demonstrated that the diverse Eemian warming

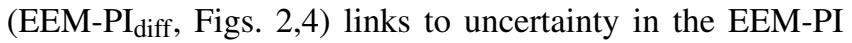
change in SSTs and sea ice. Consequently, our results support the hypothesis by Lunt et al. (2013), Otto-Bliesner et al. (2013), and Nikolova et al. (2013) that sea ice is crucial in explaining the intermodel spread in simulated Eemian warming. From the analysis so far, however, it is not possible to distinguish the impact of sea ice changes in the Labrador Sea from the ones in the Nordic Seas. To disentangle the effect of these two regions, we make use of the idealized sea ice sensitivity experiments, which simulate a sea ice retreat in either the Labrador Sea or in the Nordic Seas. In particular, we are interested in which sea ice retreat is responsible for the widespread temperature signal that extends to Greenland.

The idealized LabS-shift leads to a distinct winter sea ice reduction in the Labrador Sea accompanied by a SST increase of up to $5^{\circ} \mathrm{C}$ (Fig. 6a). Equivalent to the processes explained in Sect. 4.3, changes in lower boundary conditions act as local heat sources with anomalous surface heat fluxes transporting heat out of the ocean into the overlying atmosphere (Fig. 6b-d). Thereby, the key contribution to the net surface energy flux change (Fig. 6b) is again made by the turbulent energy fluxes (Fig. 6c, d). The positive (upward) net surface energy flux anomaly is strongest directly above the sea ice retreat (Fig. 6a) but also spreads to the Baffin Bay area. The latter is explained by considering that, in summer and autumn, the sea ice edge lies in this more northern region (see Fig. 3) and consequently the LabS-shift results in a distinct seasonal sea ice retreat in these more northern areas (not shown). The summer/autumn sea ice reduction also affects the winter heat fluxes as the simulated snow cover accumulated on the Baffin Bay sea ice is highly reduced in EEM $_{\text {LabS }}$ compared to the reference simulation, where snow can accumulate all year (not shown). As the snow cover also acts as a thermal insulation layer between the warm ocean and the cold atmosphere, a thinner snow layer leads to an increase in the local sensible heat flux (Fig. 6c). Furthermore, both turbulent heat fluxes exhibit again the dipole structure with negative flux anomalies in the area west of the Labrador Sea.

Correspondingly, the NordS-shift experiment (Fig. 6e-h) exhibits distinct SIC, SST, and energy flux anomalies in the Nordic Seas. The perturbation results in a sea ice retreat 

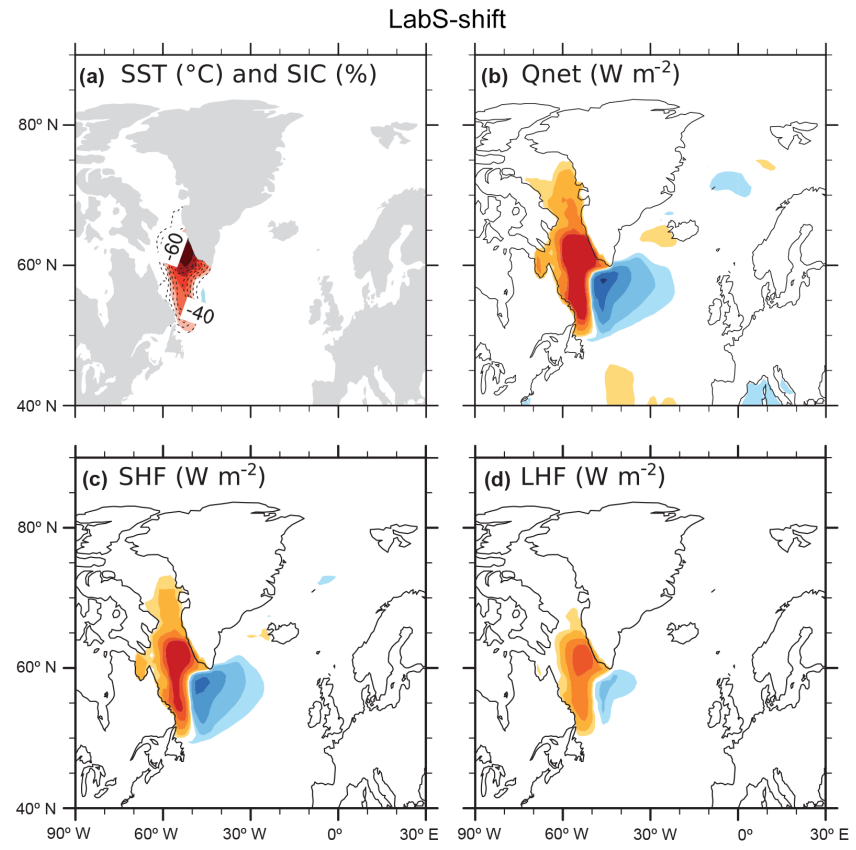

NordS-shift
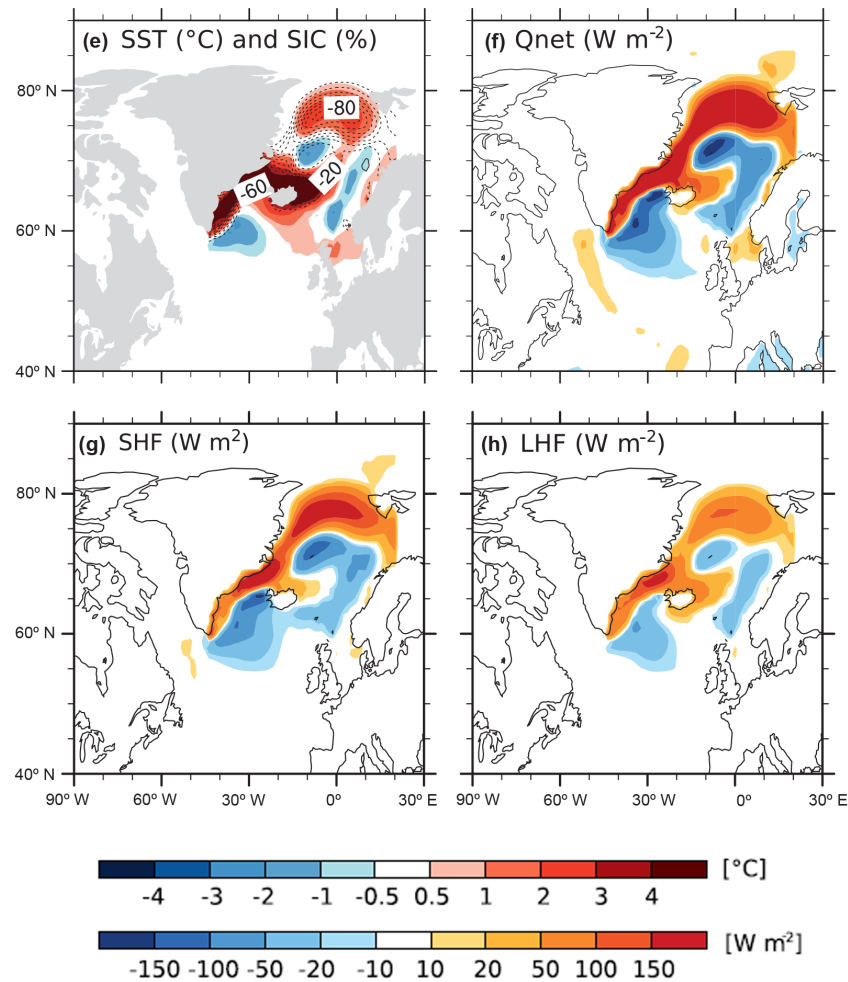

Figure 6. Same as Fig. 5 but for the LabS-shift response (a-d) and the NordS-shift response (e-h).

along the East Greenland coast, around Iceland, and in the Fram Strait (Fig. 6e). The areas of SIC reduction coherently show an increase in SSTs, whereas other areas in the Nordic Seas experience a moderate cooling of the surface ocean as a result of the SST shift included in EEM $_{\text {NordS. In agreement }}$ with the previous results, strong positive net surface energy flux anomalies (Fig. 6f) are simulated for all regions with decreasing SIC, with sensible and latent heat (Fig. 6g, h) together accounting for most of this energy flux increase. At the same time, a decrease in the energy fluxes is found in areas adjacent to the sea ice reductions building the dipole

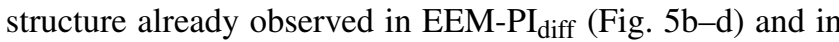
the LabS-shift experiment (Fig. 6b-d).

The net surface energy flux response of the LabS- and NordS-shift experiments (Fig. $6 \mathrm{~b}$ and f) confirms that our idealized sea ice shift experiments lead to distinct winter heat sources located either west (LabS) or east (NordS) of Greenland. With regard to the predominantly westerly flow in the $\mathrm{NH}$ extratropical atmosphere, one intuitively expects that heat released upstream of Greenland (i.e., in the LabS) spreads to Greenland rather than heat released downstream of Greenland (i.e., in the NordS). The simulated SAT response to the two shift experiments, however, reveals a different picture (Fig. 7): the LabS-shift leads to a surface warming above the Labrador Sea/Baffin Bay area but hardly any warming over the adjacent land masses. Over Greenland, significant warming is limited to the western coastal regions that have direct contact to the heat source in the Labrador Sea (Fig. 7a). In contrast, the SAT response to the NordS-shift (Fig. 7b) reveals an atmospheric surface warming that substantially extends beyond the heat source area (i.e., the positive Qnet anomalies in Fig. 6b). The NordS-shift SAT response shows significant warming all over Greenland, Baffin Bay, and the northeastern North Atlantic.

\subsection{Heat budget}

To understand the SAT response of the two sea ice shift experiments, we consider the atmospheric heat budget. The heat budget is based on the thermodynamic energy equation (TEE) in which the conservation of energy is applied to a moving fluid (Holton, 2004):

$$
\frac{\delta \mathbf{T}}{\delta t}=-\boldsymbol{v} \times \nabla \mathbf{T}-\frac{\delta \mathbf{T}}{\delta p} \omega+\frac{\alpha}{c_{\mathrm{p}}} \omega+\frac{J}{c_{\mathrm{p}}} .
$$

The terms of the TEE consist of the horizontal $(-\boldsymbol{v} \times \nabla \mathbf{T})$ and vertical $\left(-\frac{\delta \mathbf{T}}{\delta p} \omega\right)$ heat temperature advection, the adiabatic compression $\left(\frac{\alpha}{c_{\mathrm{p}}} \omega\right)$ resulting from a vertical displacement of an air parcel, and diabatic processes $\left(\frac{J}{c_{\mathrm{p}}}\right)$ such as radiative or latent heating. Within the CAM4 model the heat budget is calculated considering modifications to the TEE as the physical principles are employed in a numerical modeling framework and certain processes need to be parameterized. For example, turbulence in the atmospheric boundary level is not resolved and consequently this transport is parameterized. Taking this into account, we use the simplified description of the CAM4 heat budget:

$$
\frac{\delta \mathbf{T}}{\delta t}=\mathrm{HT}_{\text {res }}+\mathrm{HT}_{\mathrm{par}}+\frac{J}{c_{\mathrm{p}}} .
$$



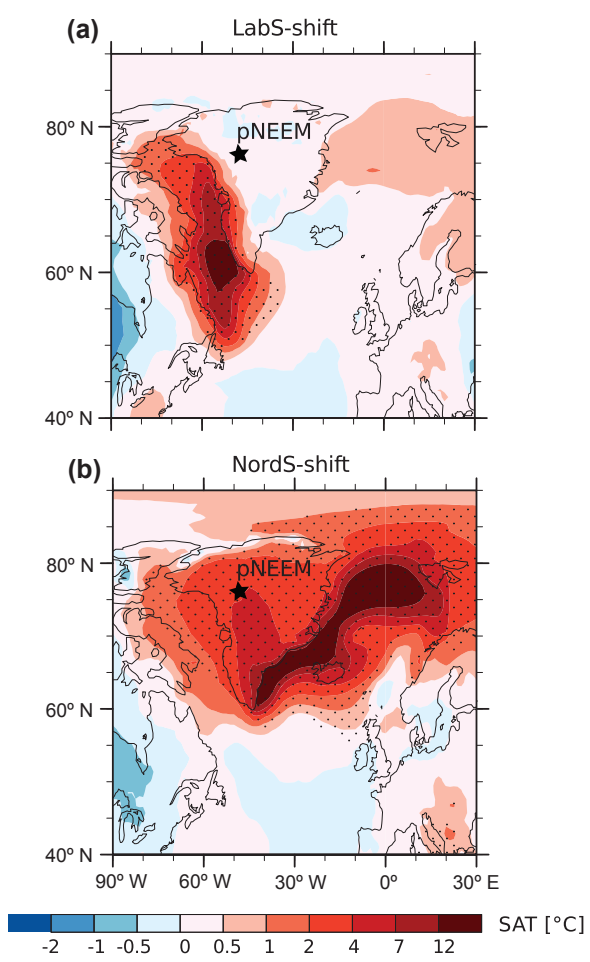

Figure 7. (a) LabS-shift and (b) NordS-shift response in winter (DJF) mean surface air temperature (SAT). Stippling denotes values significant at the $5 \%$ level based on $t$ test statistics.

In Eq. (2) the first three terms of the right-hand side of the TEE (Eq. 1) are replaced with the heat transport resolved within the CAM4 dynamical core $\left(\mathrm{HT}_{\mathrm{res}}\right)$ and the heat transport due to parameterized processes $\left(\mathrm{HT}_{\mathrm{par}}\right)$. The latter mainly represents vertical heat transport due to sub-grid eddies. Note that all simulations are run into equilibrium, so the total temperature tendency $(\delta \mathbf{T} / \delta t)$ is zero.

The CAM4 heat budget response for both sea ice shift experiments is shown in Fig. 8 for the lowest terrain-following level. The heat budget response to the LabS-shift experiment (Fig. 8a-c) indicates that, over the Labrador Sea/Baffin Bay area, $\mathrm{HT}_{\mathrm{par}}$ is the dominant process to vertically transport heat from the ocean surface to the overlying low-level atmosphere. In contrast, $\mathrm{HT}_{\text {res }}$ is responsible for carrying the excess heat away from the heat source area. This heat mainly accumulates in the North Atlantic area located south of Greenland, where it is vertically mixed to the surface by sub-grid eddies (measured by $\mathrm{HT}_{\mathrm{par}}$ ) and, eventually, negative heat flux anomalies (Fig. 6b) that transfer the energy excess out of the atmosphere into the ocean. Furthermore, the warming in western Greenland (Fig. 7a) is related to enhanced $\mathrm{HT}_{\text {par }}$ (Fig. 8b).

The response of the CAM4 heat budget to the NordS-shift is shown in Fig. 8d-f. Similarly to the LabS-shift experiment, the heat generated by the positive Qnet anomalies in the NordS sea ice retreat area (Fig. 6f) is vertically transported to the overlying atmosphere by $\mathrm{HT}_{\mathrm{par}}$. Further, $\mathrm{HT}_{\text {res }}$ is responsible for horizontally distributing the heat to the North Atlantic southwest of the sea ice retreat area. There, the excess heat is transported back down to the ocean surface by turbulent eddies (indicated as negative $\mathrm{HT}_{\mathrm{par}}$ anomaly, Fig. 8f) and is eventually lost to the ocean as revealed by negative Qnet anomalies (Fig. 6f). In contrast to the LabS-shift experiment, however, the sea ice retreat in the NordS also leads to distinct heat budget changes over Greenland (Fig. 8). Depending on the Greenland region, the low-level warming is caused by either enhancement of the resolved $\left(\mathrm{HT}_{\text {res }}\right)$ or the parameterized ( $\mathrm{HT}_{\mathrm{par}}$ ) heat transport (Fig. 8d, e). In contrast, diabatic processes are of secondary importance for explaining the spatial distribution of the heat released in the NordS source region (Fig. 8f). Above Greenland, the NordS-shift experiment mostly leads to a decrease in diabatic heating at low levels (Fig. 8e), whereas the diabatic heating increases in the same areas at higher levels (not shown). This is explained by the fact that, as atmospheric temperatures rise above Greenland (see Fig. 7b), condensation of moisture is vertically shifted to higher atmospheric levels. In general, most of the diabatic heating response in both shift experiments (Fig. 8c, f) can be attributed to changes in latent heating rather than radiative processes. Thus, the response of the cloud cover (which alters the radiation budget) to either sea ice perturbation is small and negligible (not shown).

Consequently, we find that moisture- and radiation-related processes are not of high relevance in explaining the presence (absence) of a warming in Greenland in the NordSshift (LabS-shift) experiment shown in Fig. 7. Instead, the warming in Greenland in the NordS-shift experiment is related to heat advection as suggested by the two heat transport terms (Fig. 8d, e). Theoretically, Greenland's warming can be caused by either direct advection of the heat from the heat source (i.e., the sea ice retreat area) or changing the dynamics of the atmospheric flow above Greenland. Whereas the first process alters heat advection by changing temperature gradients, the latter has an impact on heat advection by changing the flow itself. In order to analyze these processes in detail, we consider the low-level winds in and around Greenland (Fig. 9).

The atmospheric circulation in the NH during Eemian winters is similar to present-day winters (Merz et al., 2014a). The dominant circulation in Greenland is a stationary high-pressure system, known as the Greenland anticyclone (Hobbs, 1945). Accordingly, Greenland's wind field in the lower troposphere is characterized by strong winds that encircle Greenland clockwise, whereas vertical winds indicate subsidence above the margins of the Greenland ice sheet (Fig. 9a). The Greenland anticyclone can hence be regarded as an isolated wind system that hinders the exchange of heat and moisture between Greenland and adjacent areas. In the case of the LabS-shift experiment, the warming in the LabS area scarcely leads to enhanced heat advection to Greenland because the winter mean winds do not point towards Green- 

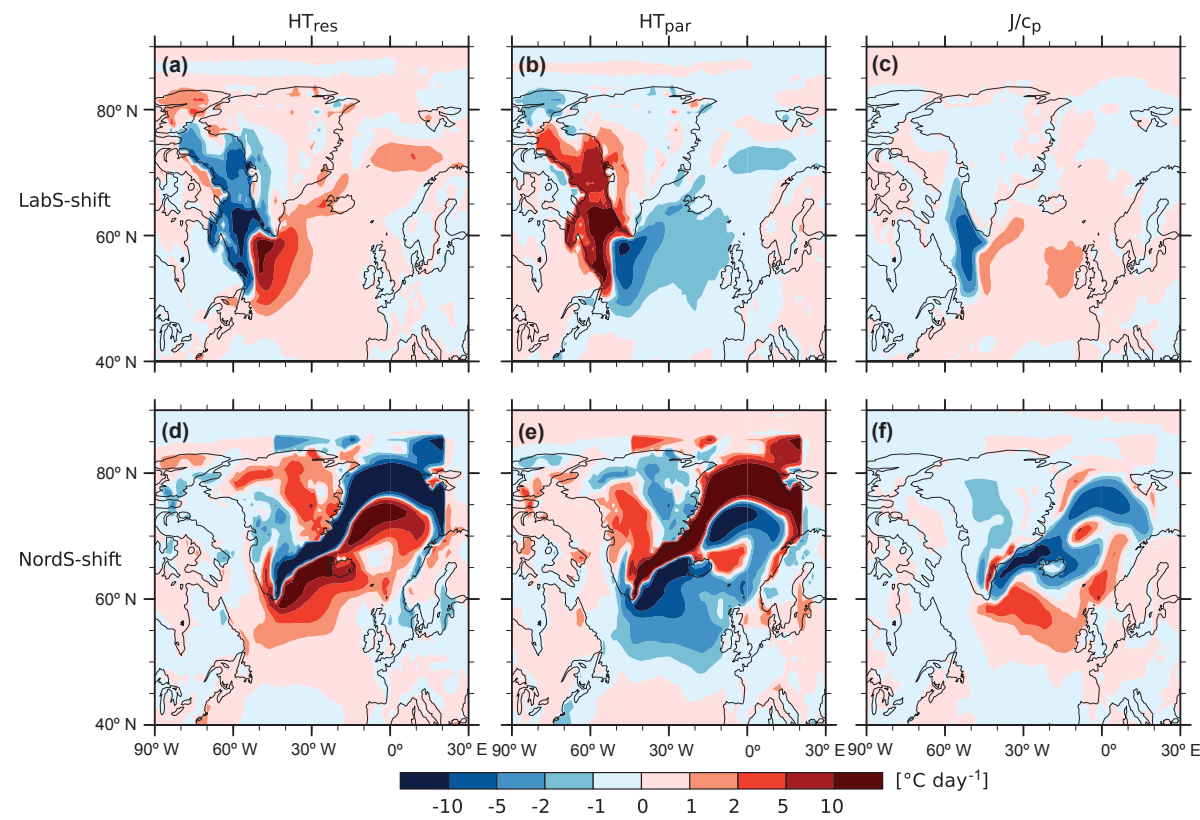

Figure 8. LabS-shift and NordS-shift response in winter (DJF) mean CAM4 heat budget components as given in Eq. (2) at the lowest terrainfollowing model level: temperature tendencies associated with $(\mathbf{a}, \mathbf{d})$ heat transport resolved within the CAM4 dynamical core (HT $\left.\mathrm{C}_{\mathrm{res}}\right)$, (b, e) heat transport due to CAM4 parameterizations $\left(\mathrm{HT}_{\mathrm{par}}\right)$, and $(\mathbf{c}, \mathbf{f})$ diabatic processes $\left(\frac{J}{c_{\mathrm{p}}}\right)$.

land but rather to the North Atlantic areas located southeast (see vectors in Fig. 9a). There, enhanced heat advection is found based on the heat budget calculation (Fig. 8a), causing a local warming (Fig. 7a). The dynamic response of the winds in the LabS-shift experiment (Fig. 9b) even shows an intensification of the northwesterly winds in the LabS area and implies an additional strengthening of the heat advection in the southeasterly direction. In contrast, the low-level winds hardly change above Greenland and thus there is also no dynamic response of the atmospheric flow in the LabSshift experiment that would result in a significant temperature response in Greenland.

The Greenland anticyclone also acts as a barrier for heat approaching Greenland from the NordS area. The low-level winds east of Greenland indicate southward flow along Greenland's east coast (Fig. 9a) which further relates to the Iceland low-pressure system. Consequently, the winter mean circulation transports heat released in the NordS domain southwards along Greenland's coast and hence there is no direct heat transport towards central Greenland. However, the NordS-shift experiment shows distinct modifications to the low-level winds in and around Greenland (Fig. 9c): there is strong anomalous flow towards central Greenland from the North Atlantic area located to the southeast. More precisely, the shallow baroclinic response to the strong surface warming east of Greenland (Fig. 7b) leads to a surface pressure reduction over southern Greenland (not shown) and the corresponding anomalous low-level flow shown in Fig. 9c. Hence, the NordS-shift is able to substantially weaken the barrier effect of the Greenland anticyclone, so that warm air masses can enter Greenland. Accordingly, the vertical winds in Fig. 9c show anomalous upward motion in southeastern Greenland as the onshore winds are lifted over the steep margins of the ice sheet.

In summary, the sea ice perturbation of the NordS-shift experiment is able to substantially alter the atmospheric flow above Greenland leading to a change in heat transport (as indicated by the $\mathrm{HT}_{\text {res }}$ and $\mathrm{HT}_{\text {res }}$ anomalies in Fig. 8d, e). This, eventually, is responsible for the large-scale warming seen in Fig. 7b. In contrast, the dynamic response to the LabS-shift does not foster anomalous heat advection towards Greenland, and thus the Greenland SAT response in this experiment is very limited (see Fig. 7a).

\subsection{Moisture budget}

Despite the result that moisture-related processes are not of high importance to explain the warming in either sea ice experiment (as explained in Sect. 5.1), the response of the hydrological cycle to the sea ice perturbations is substantial (Fig. 10). Changes in the hydrological cycle are described in terms of the atmospheric moisture budget, which states that any change in moisture accumulation, defined as precipitation minus evaporation $(P-E)$, must be compensated for by moisture advection. The latter is calculated as the convergence of the vertically integrated zonal and meridional moisture fluxes. This calculation is based on daily model output using finite differences. 

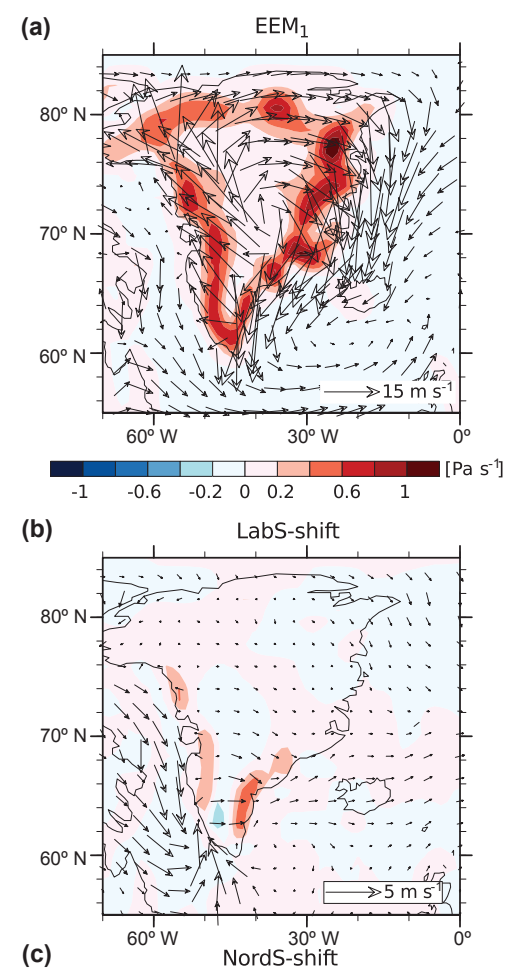

(c)

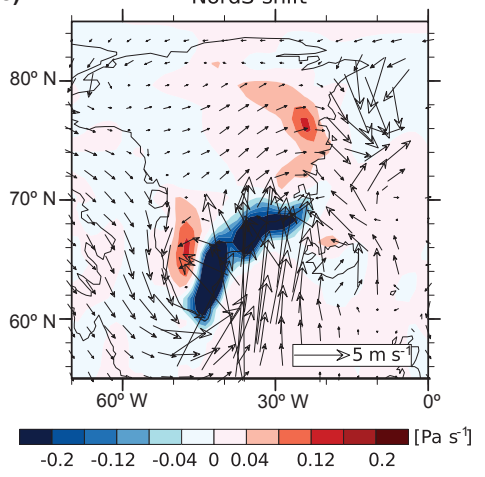

Figure 9. Winter (DJF) mean vertical (shaded) and horizontal (vectors) wind velocities at lowest terrain-following model level for (a) $\mathrm{EEM}_{1}$, (b) LabS-shift response, and (c) NordS-shift response. Positive (negative) vertical wind velocities denote downward (upward) motion.

The LabS-shift response in $P-E$ shows that, in the LabS area, evaporation dominates over a concurrent precipitation increase (Fig. 10a). Hence, the sea ice retreat area acts as an atmospheric moisture source in addition to its role as a heat source. The excess moisture is mainly transported eastwards (Fig. 10b) and deposited either in the North Atlantic in the southeast or in western Greenland. While the eastward transport roughly corresponds to the winter mean circulation indicated by the horizontal winds in Fig. 9a, the moisture advection to Greenland is due to synoptic systems (i.e., cyclones) that occasionally transport substantial amounts of moisture northwards along Greenland's west coast (Hutterli et al., 2005; Tsukernik et al., 2007).

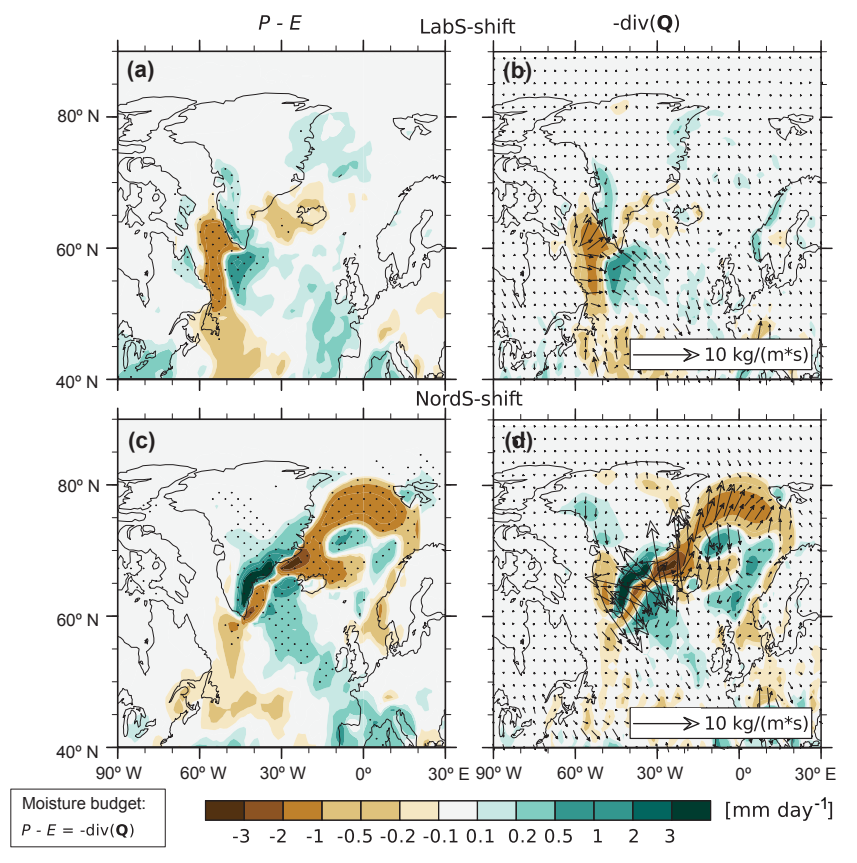

Figure 10. LabS-shift and NordS-shift response in winter (DJF) mean moisture budget: (a) and (c) denote precipitation minus evaporation $(P-E)$; (b) and (d) show the vertically integrated moisture fluxes (vectors) and their convergence $(-\operatorname{div}(\boldsymbol{Q})$, shaded), respectively. Stippling in (a) and (c) indicates $P-E$ changes significant at the $5 \%$ level based on $t$ test statistics.

The response of the hydrological cycle to the sea ice shift in the NordS exhibits similar changes: in the areas of sea ice reduction, increased evaporation (as also apparent in the latent heat flux, Fig. 6h) dominates over precipitation changes leading to distinctively negative $P-E$ anomalies (Fig. 10c). On the other hand, positive $P-E$ anomalies and hence increased moisture deposition are simulated for other areas in the North Atlantic and in Greenland related to corresponding changes in moisture advection (Fig. 10d). For Greenland, most of the additionally available moisture precipitates above the steep margins of the ice sheet in the southeast, where the moist air masses are lifted and, consequently, cause orographic precipitation. The resulting maximum in winter precipitation in southeastern Greenland is a prominent feature in the North Atlantic winter climate (e.g., Tsukernik et al., 2007; Merz et al., 2014b) related to a local maximum in cyclone frequency in the area of the Icelandic low. Enhanced moisture availability in the NordS domain thus results in a precipitation increase in this specific Greenland region, with cyclones being the carrier. Moreover, increased precipitation in southeastern Greenland relates to the previous result of an enhancement of the onshore winds in response to the NordSshift (Fig. 9c). Hence, the dynamic response itself fosters the advection of both heat and moisture from the Nordic Seas towards eastern Greenland. 


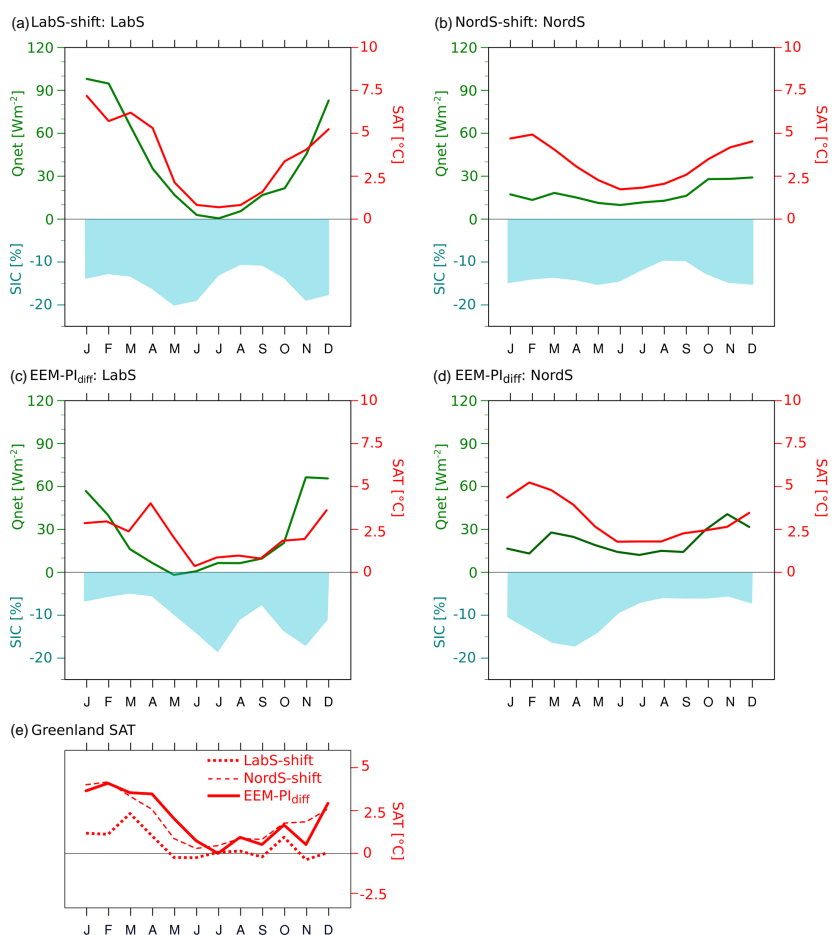

Figure 11. Annual cycle of sea ice concentration (SIC, blue shading), net surface energy flux (Qnet, green lines), and surface air temperature (SAT, red lines) anomalies: (a) LabS-shift response in the LabS domain, (b) NordS-shift response in the NordS domain, (c) EEM-PI diff $_{\text {response in the LabS domain, (d) EEM-PI }}$ diff response in the NordS domain, and (e) Greenland mean SAT in response to LabS-shift (dotted), NordS-shift (dashed), and EEM$\mathrm{PI}_{\text {diff }}$ (solid). The LabS domain comprises all oceanic grid points within the solid box in Fig. 1a and the NordS domain is the equivalent in Fig. 1b. Note that all annual cycles are calculated as spatial averages including area weighting; for example, Greenland mean SAT in (e) refers to the area-averaged SAT of the whole of Greenland.

\subsection{Seasonality}

The results presented so far show a distinct impact of regional sea ice reductions on the winter climate in the North Atlantic sector. To assess the importance of changes in sea ice cover for the interpretation of Eemian climate proxy records, which mostly reflect annual mean changes, the temporal scope will be broadened to the other seasons. In the following, we analyze the relationship between the seasonality in sea ice reduction and the seasonality of the atmospheric response. For this purpose, we compute the annual cycles of the areaaveraged SIC, Qnet, and SAT anomalies for the LabS domain (Fig. 11a, c) and the NordS domain (Fig. 11b, d). These domains are defined in Fig. 1a and $b$.

The average monthly SIC reduction in the LabS domain as a result of the idealized LabS-shift varies between 10 and $20 \%$ reduction (Fig. 11a). As previously discussed, a certain retreat in the sea ice cover reflects a change in lower boundary conditions to the atmosphere influencing the exchange of heat and moisture at the ocean-atmosphere interface. Hence, in terms of energy, the sea ice retreat is transferred to the overlying atmosphere by anomalous net surface energy fluxes (Qnet in Fig. 11a). The LabS-shift results in a distinct annual cycle of the Qnet response with the maximum increase during winter in contrast to almost no change in summer. Hence, the magnitude of the Qnet response is not tied to the concurrent SIC reduction but rather to seasonally diverse climate conditions. More precisely, we find a winter maximum in the turbulent (i.e., sensible and latent) heat flux response arising from the fact that this is the time of year when the low-level air temperatures are coolest relative to the underlying surface (sea ice or open water). Consequently, a sea ice retreat that exposes SSTs to the overlying atmosphere has a distinct "heat source effect" in the winter half-year. In contrast, this is effect is reduced in summer, when atmospheric and surface ocean temperatures are comparable. This seasonally diverse behavior of the heat flux response to changes in sea ice is well known and has previously been identified in model and reanalysis studies investigating recent and future Arctic sea ice changes (Deser et al., 2010; Screen and Simmonds, 2010; Screen et al., 2013). As expected, an increase in the net energy flux directly translates into a local SAT signal, and thus the annual cycles of Qnet and SAT strongly resemble each other (Fig. 11a). Accordingly, the maximum SAT response in the LabS domain emerges in winter $\left(>5^{\circ} \mathrm{C}\right)$ coinciding with the Qnet maximum. Conversely, the summer warming is smaller in magnitude $\left(\sim 1^{\circ} \mathrm{C}\right)$.

Equivalently to the LabS-shift experiment, the NordS-shift results in a SIC reduction in the range of 10-15\% throughout the year (Fig. 11b). However, the Qnet response to the NordS-shift lacks the winter maximum previously found for the LabS-shift (compare Fig. 11a and b). This is explained by the dipole effect in turbulent heat fluxes (see Fig. $6 \mathrm{~g}, \mathrm{~h}$ ): the strongly positive heat flux anomalies in the sea ice retreat areas are partly offset by negative anomalies in adjacent areas when averaging across the NordS domain (as done in Fig. 11b). In contrast, in the LabS-shift experiment the negative part of the heat flux dipole is located outside of the LabS domain (see Fig. 6c, d) and hence not considered in the calculation of the Qnet values shown in Fig. 11a. Nevertheless, the seasonality of the SAT response to the NordS-shift (Fig. 11b) is similar to the LabS-shift experiment, with a winter maximum and a summer minimum, respectively.

In summary, we find that a sea ice retreat substantially influences the local winter climate in both regions, whereas the response of the summer climate is smaller in amplitude. The same result is true for EEM-PI diff (Table 2), as shown by the annual cycles in Fig. 11c and d. Hence, although EEM-PI ${ }_{\text {diff }}$ exhibits a sea ice reduction in any season and not mostly distinctively in winter, the Qnet and SAT response is largest in the cold season. In the LabS domain, the winter sea ice reduction corresponding to EEM-PI ${ }_{\text {diff }}$ is considerably smaller 
than for the LabS-shift experiment (compare Fig. 11a and c) and, accordingly, the Qnet and SAT maxima in winter are less

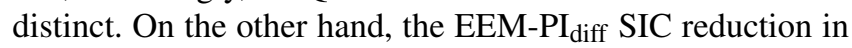
the NordS domain during winter is in the same range as in the NordS-shift experiment (compare Fig. 11b and d), so the respective SAT responses are similar in magnitude as well. The comparability of the results of EEM-PI $I_{\text {diff }}$ and the two shift experiments further illustrates the utility of the idealized sea ice sensitivity experiments for identifying the impact of regional sea ice changes on the Eemian climate.

In addition to the seasonality of sea ice changes and its response on the overlying atmosphere, we assess the annual cycle in Greenland's SAT response (Fig. 11e). In contrast to the SAT response in the area of sea ice perturbation (i.e., the LabS or NordS), which is the direct result of altered surface energy fluxes, a change in Greenland temperatures additionally requires anomalous heat transport (as discussed in Sect. 5.1). The EEM-PI ${ }_{\text {diff }}$ Greenland SAT response shows a distinct warming in winter/spring but only a moderate warming during the warm season. Furthermore, the NordS-shift results in a very similar warming response to EEM-PI ${ }_{\text {diff }}$, confirming the previous result that a sea ice retreat in the NordS is crucial to explain the widespread warming seen in EEM$\mathrm{PI}_{\text {diff }}$ (Fig. 4 bottom row). In contrast, the sea ice perturbation caused by the LabS-shift only leads to a very moderate Greenland warming. Hence, despite the distinct local winter warming caused by the LabS-shift (Fig. 11a) the absence of a heat transport towards Greenland prevents a concurrent Greenland warming in any season (Fig. 11e).

\subsection{Impact of experimental design}

As introduced in Sect. 3, we perform additional sea ice sensitivity experiments in which we test modifications to the sea ice shift approach. The results of these simulations with respect to the SAT response in the area of sea ice perturbation (LabS or NordS) as well as in Greenland are listed in Table 3.

In $\mathrm{EEM}_{\mathrm{LabS2}}$ and $\mathrm{EEM}_{\mathrm{NordS2}}$ we use the $\mathrm{EEM}_{2}$ lower boundary conditions as a baseline to apply the shift instead of those of $E \mathrm{EM}_{1}$ used so far for $\mathrm{EEM}_{\mathrm{LabS}}$ and

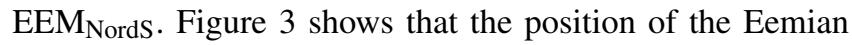
sea ice edge in $\mathrm{EEM}_{1}$ differs from $\mathrm{EEM}_{2}$. Applying the shift to the latter thus results in a change of the location of the sea ice anomalies and hence in the location of the strongest heat flux anomalies (i.e., the heat source). In $E M_{L a b S 2}$ and $E M_{\text {NordS2 }}$ the resulting heat source regions are shifted northwards with respect to $\mathrm{EEM}_{\mathrm{LabS}}$ and

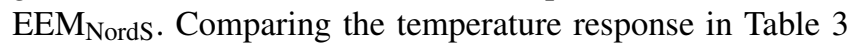
of $\mathrm{EEM}_{\mathrm{LabS} 2} / \mathrm{EEM}_{\mathrm{LabS}}$ and $\mathrm{EEM}_{\mathrm{NordS} 2} / \mathrm{EEM}_{\mathrm{NordS}}$, we find that shifting the position of the heat source area only has a moderate effect on the local warming as well as on the response in Greenland. Still, a northward shift of the heat source area seems to reduce the magnitude of warming.

Moreover, we generate four sensitivity experiments for which we shift the sea ice but not the SSTs in order to exclude the response to a (possibly overestimated) surface ocean warming that comes along with the SST shift. Accordingly, in these simulations (denoted with an ICE suffix in Table 3) the heat source is restricted to the area of sea ice retreat as the SST anomalies shown in Fig. 6a and 6e are omitted. In the LabS region this model setup appears to be of minor importance as the warming response in both ICE simulations does not deviate from the response in the experiments including the SST shift. In contrast, the effect is much larger for the NordS-shift experiment, where ignoring the widespread SST increase (shown in Fig. 6e) substantially reduces the strength of the heat source. Consequently, the ICE simulations generate a smaller temperature response compared to the simulations including the SST shift.

Our whole set of sensitivity experiments covers a reasonable range of possible sea ice (and related SST) changes in the two target regions. The following results are robust among all simulations as shown in Table 3. (i) A sea ice reduction in the LabS domain leads to a strong local warming (DJF: $5.3-6.0^{\circ} \mathrm{C}$; annual: $2.3-3.6^{\circ} \mathrm{C}$ ). (ii) The response in Greenland temperature to a perturbation in the LabS is limited due to the lack of heat transport towards Greenland. The annual mean Greenland SAT increase of $0.4-0.5^{\circ} \mathrm{C}$ is still a significant warming but mostly reflects the warming in western Greenland shown in Fig. 7a. (iii) In the NordS region the strength of the heat source depends on the specific experimental setting (i.e., inclusion/exclusion of SST changes, location of the perturbation). This results in a considerable spread in the NordS temperature response (DJF: $2.3-4.6^{\circ} \mathrm{C}$; annual: $1.2-3.1^{\circ} \mathrm{C}$ ). (iv) Correspondingly, there is a spread in terms of warming in Greenland (DJF: $1.1-3.8^{\circ} \mathrm{C}$; annual: 0.6-2. $1{ }^{\circ} \mathrm{C}$ ) depending on the strength of the heat source in the NordS. (v) The impact of the NordS-shift on the Greenland SAT exceeds the influence of the LabS-shift in all cases considered here.

As a next step, we compare the temperature responses of

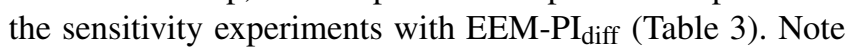

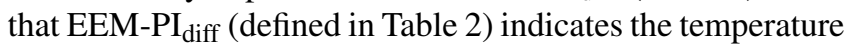
response resulting from the uncertainty in EEM-PI changes in the lower boundary conditions based on two pairs of fully coupled CCSM3 simulations. The EEM-PI $\mathrm{I}_{\text {diff }}$ temperature signal in the LabS region is below the range of the sensitivity simulations, implying that the heat source employed in the idealized LabS-shift experiments is rather overestimated.

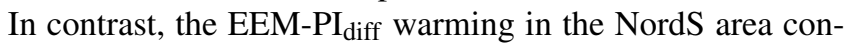
forms to the idealized experiment featuring the strongest heat

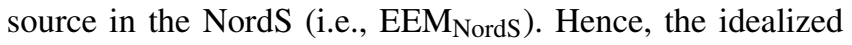
scenario of a distinct sea ice reduction and surface warming

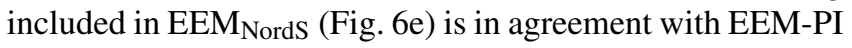
changes simulated by state-of-the-art climate models. 
Table 3. Surface air temperature (SAT) anomalies averaged above the Labrador Sea (LabS), Greenland and the Nordic Seas (NordS) for all CCSM4 sensitivity experiments compared to the respective control experiments (e.g., $E_{\text {EMabS }}=$ EEM $_{\text {LabS }}-$ EEM $_{1}$ ). Please refer to Sects. 2.2 and 5.4 for details about the simulations. Bold values indicate anomalies significant at the $5 \%$ level based on $t$ test statistics.

\begin{tabular}{lcc|cc||cc}
\hline \multirow{2}{*}{ Simulation } & \multicolumn{2}{c|}{ LabS $\Delta$ SAT $\left({ }^{\circ} \mathrm{C}\right)$} & \multicolumn{2}{|c|}{ Greenland $\Delta$ SAT $\left({ }^{\circ} \mathrm{C}\right)$} & NordS $\Delta$ SAT $\left({ }^{\circ} \mathrm{C}\right)$ \\
\cline { 2 - 7 } & DJF & annual & DJF & annual & DJF & annual \\
\hline EEM $_{\text {LabS }}$ & $\mathbf{6 . 0}$ & $\mathbf{3 . 6}$ & 0.7 & $\mathbf{0 . 4}$ & & \\
EEM $_{\text {LabS2 }}$ & $\mathbf{5 . 4}$ & $\mathbf{2 . 8}$ & $\mathbf{0 . 9}$ & $\mathbf{0 . 5}$ & & \\
EEM $_{\text {LabS ICE }}$ & $\mathbf{5 . 3}$ & $\mathbf{2 . 9}$ & 0.7 & $\mathbf{0 . 5}$ & & \\
EEM $_{\text {LabS2 ICE }}$ & $\mathbf{5 . 7}$ & $\mathbf{2 . 3}$ & 0.5 & $\mathbf{0 . 4}$ & & \\
EEM $_{\text {NordS }}$ & & & $\mathbf{3 . 8}$ & $\mathbf{2 . 1}$ & $\mathbf{4 . 6}$ & $\mathbf{3 . 1}$ \\
EEM $_{\text {NordS2 }}$ & & & $\mathbf{3 . 0}$ & $\mathbf{2 . 0}$ & $\mathbf{3 . 2}$ & $\mathbf{2 . 3}$ \\
EEM $_{\text {NordS ICE }}$ & & & $\mathbf{2 . 2}$ & $\mathbf{0 . 9}$ & $\mathbf{3 . 8}$ & $\mathbf{2 . 0}$ \\
EEM $_{\text {NordS2 ICE }}$ & & & $\mathbf{1 . 1}$ & $\mathbf{0 . 6}$ & $\mathbf{2 . 3}$ & $\mathbf{1 . 2}$ \\
EEM-PI $_{\text {diff }}$ & $\mathbf{2 . 9}$ & $\mathbf{1 . 8}$ & $\mathbf{2 . 8}$ & $\mathbf{1 . 5}$ & $\mathbf{4 . 4}$ & $\mathbf{3 . 3}$ \\
\hline
\end{tabular}

\section{Discussion}

The results show how the representation of the lower boundary conditions (i.e., sea ice and SSTs) is crucial for the simulated warming during the Eemian, particularly in the North Atlantic. Substantially warmer than present annual mean SATs during the Eemian, as observed in proxy records (e.g., Turney and Jones, 2010), require warmer than present SSTs and a reduced sea ice cover. Note that the external forcing of the Eemian consists of an anomalous orbital forcing leading to seasonally diverse insolation anomalies and lower than present GHG concentrations (Lunt et al., 2013, and references therein). The direct effect of the climate system to this external forcing alone does not explain a yearround Eemian warming. Instead, positive feedbacks associated with changes in sea ice, land ice, snow cover, and vegetation changes are required, especially to explain the distinct warming observed in the $\mathrm{NH}$ high latitudes resulting in a polar amplification pattern (CAPE Last Interglacial Project Members, 2006).

In this study, we show for the CCSM3 model that differences in the simulation of the lower boundary conditions explain most of the spread with respect to the EEM-PI atmospheric warming in the North Atlantic sector including Greenland (see Fig. 2 and text in Sect. 4). Hence, feedbacks and changes in the model's ocean and sea ice component clearly influence the magnitude of the Eemian warming in the atmosphere. We hypothesize that the same is true for the remarkable spread found among the wide range of models in Lunt et al. (2013). Furthermore, a climate model which, for the Eemian, simulates warmer SSTs and a reduced sea ice cover, and consequently a stronger atmospheric warm-

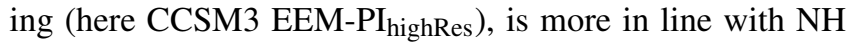
proxy records (Turney and Jones, 2010). This is true with respect to both marine and terrestrial temperature proxies. The picture, however, gets complicated when comparing models and proxy data on a regional scale as the proxies ex- hibit a wide range of Eemian minus preindustrial temperature anomalies at similar latitudes (Otto-Bliesner et al., 2013; Lunt et al., 2013). Besides the spatial variability, a further degree of complexity arises when considering the temporal evolution of the temperature proxy records throughout the Eemian, which are rarely represented correctly in the models (Capron et al., 2014).

Another specific goal of this study is to assess the impact of sea ice changes on the climate in Greenland and its implications for temperature records derived from Greenland ice cores. Currently, the NEEM core (NEEM community members, 2013) is the only Greenland ice core covering the entire Eemian period. The Eemian ice in NEEM was originally deposited at pNEEM (Merz et al., 2014a, b), a location ca. $300 \mathrm{~km}$ upstream of NEEM and relatively close to the summit of the ice sheet. Consequently, we are interested in the simulated Eemian climate at pNEEM, located approximately at $76^{\circ} \mathrm{N}, 44^{\circ} \mathrm{W}$ (see Fig. 7). The temperature response at pNEEM to the shift experiments as well as to the different EEM-PI diff $_{\text {lower boundary conditions }}$ is shown in Fig. 12. This figure confirms that sea ice and SST changes in the LabS area are hardly recorded on top of the Greenland ice sheet in contrast to the NordS-shift ex-

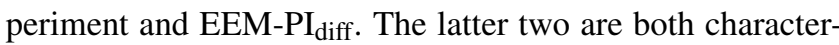
ized by distinct sea ice reductions in the NordS area, leading to a notable atmospheric warming above the oceans east of Greenland (Fig. 12b, c). Furthermore, the dynamical response of the atmosphere to the sea ice perturbation in the NordS area results in a widespread temperature response as the additionally available heat spreads over the lower troposphere of the North Atlantic and thus also to the Greenland ice core sites, including pNEEM. Consequently, temperature records based on Greenland ice cores are sensitive to sea ice changes in the NordS area but rather insensitive to sea ice changes in the LabS area. This is consistent with results by $\mathrm{Li}$ et al. (2010), who reported similar findings for glacial climate conditions. Hence, the demonstrated relation- 

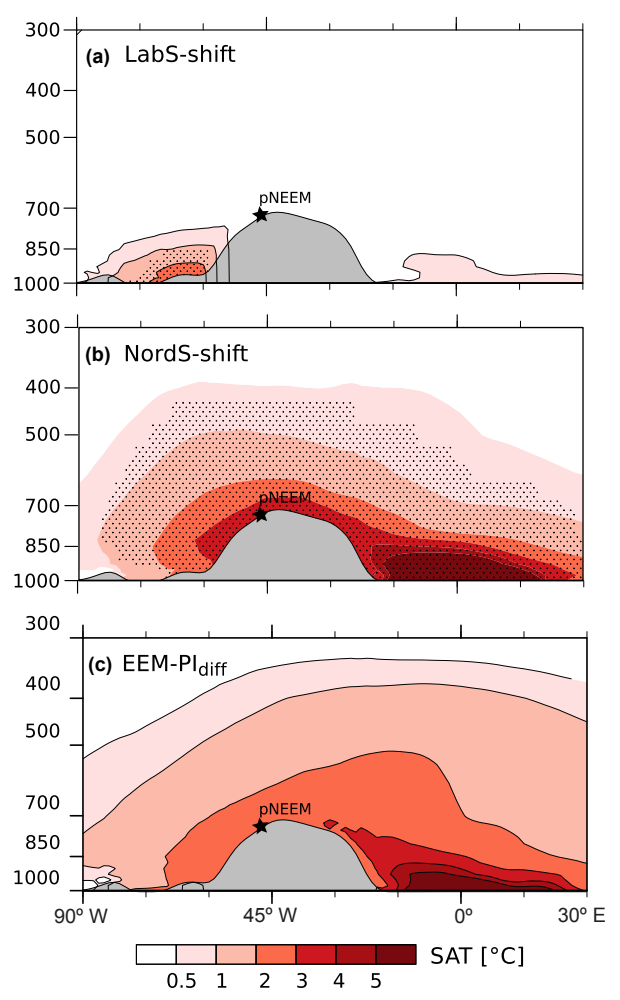

Figure 12. (a) LabS-shift, (b) NordS-shift, and (c) EEM-PI $\mathrm{diff}_{\mathrm{d}}$ response in winter (DJF) mean temperature shown as longitudepressure cross section along the $76^{\circ} \mathrm{N}$ latitude (i.e., the latitude of pNEEM). Stippling in (a) and (b) denotes SAT changes significant at the $5 \%$ level based on $t$ test statistics.

ship between Greenland temperature and sea ice in the adjacent oceanic areas is not limited to the Eemian but very likely valid for any interglacial and glacial climate period where sea ice changes in the Nordic Seas have occurred.

Quantitative estimates of sea-ice-induced annual mean SAT changes in central Greenland, including the pNEEM site, are further shown in Table 4. All LabS-shift experiments result in a statistically non-significant warming of at most $0.3^{\circ} \mathrm{C}$. In contrast, the NordS-shift experiments all result in significant annual mean warming in the range of 0.6$2.3^{\circ} \mathrm{C}$. The magnitude of the warming in central Greenland relates to the strength of the heat source in the NordS depending on whether a warming in SSTs accompanies the sea ice reduction (see details in Sect. 5.4). The EEM NordS and EEM $_{\text {NordS2 }}$ experiments that include both sea ice and SST changes further show a significant increase in snow accumulation in central Greenland (see Table 4). This reveals the role of the NordS area as a moisture source for Greenland besides its role as a heat source. Further, this implies that oceanic changes in the NordS affect ice-core-based accumulation records.

Measurements of the Eemian $\delta^{15} \mathrm{~N}$ in the NEEM core suggest that annual mean Eemian firn temperatures were on average $5{ }^{\circ} \mathrm{C}$ warmer than at present day (NEEM community members, 2013). Based on our CCSM4 simulations we find an Eemian minus preindustrial annual mean warming in central Greenland of $0.5^{\circ} \mathrm{C}\left(\mathrm{EEM}-\mathrm{PI}_{2}\right)$ and $2.1^{\circ} \mathrm{C}\left(\mathrm{EEM}-\mathrm{PI}_{1}\right)$. Thus, the difference of $1.6^{\circ} \mathrm{C}$ for the Eemian warming relates to the different changes in the lower boundary conditions (see

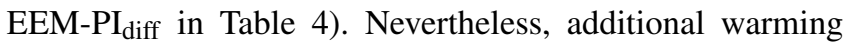
mechanisms not accounted for in this model framework are needed to explain the full magnitude of the determined $\delta^{15} \mathrm{~N}$ signal. One possibility is an even stronger reduction in the NordS sea ice than considered in EEM-PI 1 resulting in an additional warming equivalent to the NordS-shift experiments. Another possibility is the climate effect related to modifications in the Greenland ice sheet topography as Greenland must have been smaller during the Eemian to conform with observed sea level high stands (Church et al., 2013). Depending on the actual ice sheet topography this can lead to an additional annual mean warming of up to $3.1{ }^{\circ} \mathrm{C}$ at pNEEM (altitude-corrected) as demonstrated in Merz et al. (2014a). Hence, if a strong reduction in NordS sea ice coincided with a distinct retreat of the Greenland ice sheet, the full magnitude of the NEEM $\delta^{15} \mathrm{~N}$ signal can be explained. Furthermore, the sea-ice- and topography-related warming mechanisms may interact with each other as both modify Greenland's lowlevel winds. In order to assess possible feedbacks, it might be worth to generate respective model experiments that combine perturbations in sea ice with changes in the Greenland ice sheet topography. Still, it is important to note that both the sea-ice-related and the ice sheet topography-related warming mechanisms are rather of local nature and do not result in a respective warming in more distant regions, e.g., Europe. This implies that the distinct Eemian warming retrieved from the NEEM ice core should be interpreted as a local rather than hemispheric-scale climate signal.

Sea ice changes further influence the stable water isotopes measured in the NEEM core, which show a reduced depletion of at least $3 \%$ or the Eemian $\delta^{18} \mathrm{O}$ with respect to present day (NEEM community members, 2013). When we apply the temperature- $\delta^{18} \mathrm{O}$ relationship determined for the current interglacial, this translates into an Eemian temperature increase of $8 \pm 4^{\circ} \mathrm{C}$ (NEEM community members, 2013). Correspondingly, the NEEM $\delta^{18} \mathrm{O}$ record suggests an even stronger Eemian warming than measured in $\delta^{15} \mathrm{~N}$. Sime et al. (2013) showed within isotopic simulations that a reduction in the winter sea ice cover around the northern half of Greenland, together with an increase in SSTs in the same region, is sufficient to cause a $>3 \%$ interglacial enrichment of $\delta^{18} \mathrm{O}$ in central Greenland snow. The changes in SST and sea ice further lead to higher $\delta^{18} \mathrm{O}$-temperature gradients, so a $>3 \%$ enrichment in $\delta^{18} \mathrm{O}$ might rather correspond to a $5^{\circ} \mathrm{C}$ warming, which would be more in line with $\delta^{15} \mathrm{~N}$. The underlying mechanism is that a reduction in sea ice increases the fraction of water vapor deposited in central Greenland originating from more local (isotopically enriched) sources at the expense of more distant (isotopically depleted) sources (Sime et al., 2013). However, a meaningful interpretation of 
Table 4. Surface air temperature (SAT) and accumulation $(P-E)$ anomalies averaged above central Greenland for all CCSM4 sensitivity experiments compared to the respective control experiments (e.g., $E_{E M_{L a b S}}=E_{E M_{L a b S}}-E_{E M}$ ). Please refer to Sects. 2.2 and 5.4 for details about the simulations. Note that Central Greenland is defined as $70-77^{\circ} \mathrm{N}, 35-45^{\circ} \mathrm{W}$ covering the summit area that includes the pNEEM, NGRIP, and GRIP ice core sites. Bold values indicate anomalies significant at the $5 \%$ level based on $t$ test statistics.

\begin{tabular}{lcc}
\hline Simulation & $\begin{array}{c}\text { Central Greenland } \\
\text { annual } \\
\Delta \text { SAT }\left({ }^{\circ} \mathrm{C}\right)\end{array}$ & $\begin{array}{c}\text { Central Greenland } \\
\text { annual } \\
\Delta(P-E)(\%)\end{array}$ \\
\hline EEM $_{\text {LabS }}$ & 0.1 & 3 \\
$\mathrm{EEM}_{\text {LabS2 }}$ & 0.2 & 2 \\
$\mathrm{EEM}_{\text {LabS ICE }}$ & 0.2 & 3 \\
$\mathrm{EEM}_{\text {LabS2 ICE }}$ & 0.3 & 5 \\
$\mathrm{EEM}_{\text {NordS }}$ & $\mathbf{2 . 3}$ & $\mathbf{1 2}$ \\
$\mathrm{EEM}_{\text {NordS2 }}$ & $\mathbf{2 . 3}$ & $\mathbf{1 0}$ \\
$\mathrm{EEM}_{\text {NordS ICE }}$ & $\mathbf{0 . 8}$ & 1 \\
$\mathrm{EEM}_{\text {NordS2 ICE }}$ & $\mathbf{0 . 6}$ & 5 \\
$\mathrm{EEM}$ PI $_{\text {diff }}$ & $\mathbf{1 . 6}$ & \\
\hline
\end{tabular}

the NEEM $\delta^{18} \mathrm{O}$ record is further complicated by the fact that the Eemian warming in Greenland mainly occurs in summer (due to orbital forcing) but $\delta^{18} \mathrm{O}$ is rather tied to winter temperatures (Sjolte et al., 2014). Further, there are possible interferences with changes in precipitation seasonality or the inversion temperature relationship (Pausata and Loefverstroem, 2015).

\section{Summary}

We have analyzed the response of the atmospheric component of the CCSM4 climate model to Eemian lower boundary conditions (i.e., sea ice and SSTs) as well as a set of idealized sea ice retreat scenarios. The overarching goal of the study was to quantify the atmospheric warming in and around Greenland related to uncertainty in the Eemian sea ice cover. The main findings are as follows:

- The magnitude of the simulated Eemian warming in the North Atlantic region strongly depends on concurrent changes in sea ice and SSTs. Fully coupled models which simulate higher SSTs and a retreating sea ice cover for the Eemian with respect to the preindustrial era also show a stronger atmospheric warming. These simulations are in better agreement with Eemian SST and SAT proxy records from the NH extratropics.

- The effect of sea ice and SSTs on the climate is strongest in winter due to the maximum response of the surface energy fluxes during the colder season.

- Greenland temperatures are strongly influenced by the sea ice cover and SSTs in the Nordic Seas. In contrast, the impact of the Labrador Sea sea ice on the Greenland climate is marginal.

- Anomalous heat advection is the primary process to explain the large-scale warming found in response to a sea ice retreat in the Nordic Seas. Despite the fact that a sea ice retreat also has a significant impact on the North Atlantic moisture budget, anomalous diabatic heating associated with condensation processes is small and of lower-order importance for the simulated temperature response.

- The Greenland anticyclone acts as a barrier for heat and moisture approaching Greenland and hinders a sea-iceinduced warming in the Labrador Sea from spreading towards central Greenland. In contrast, the sea ice retreat in the Nordic Seas has a greater effect on the atmospheric dynamics in Greenland, resulting in anomalous winds that break up the anticyclone and allow a widespread Greenland warming.

- The Eemian annual mean warming of $5{ }^{\circ} \mathrm{C}$ above present day derived from the NEEM $\delta^{15} \mathrm{~N}$ record is consistent with CCSM4 model simulations for the scenario that a retreat in the Nordic Sea sea ice (shown here) coincided with the warming associated with a substantial reduction in the Greenland ice sheet (shown in Merz et al., 2014a). The model emphasizes that this distinct Greenland warming is mostly a local signal.

Note that our experiments only address the direct impact of a North Atlantic sea ice retreat on the surface climate and atmospheric circulation and hence neglect potential oceanic feedbacks. We are, however, confident that our results are robust as the dominant mechanism, which thermally transfers sea ice anomalies to the atmosphere (i.e., anomalous turbulent heat fluxes), is similar in fully coupled and atmosphereonly simulations (Deser et al., 2010; Petrie et al., 2015). Further evidence for the validity of the used sea ice sensitivity approach stems from the fact that the relationship between Nordic Seas sea ice and Greenland temperatures in a glacial climate is consistent among atmospheric (Li et al., 2010) and fully coupled simulations (Zhang et al., 2014). Nevertheless, it would be interesting to repeat the sea ice sensitivity experiments presented here in a fully coupled model framework, e.g., analogous to Lehner et al. (2013), in order to assess the consequences for the ocean circulation and respective feedbacks to the atmosphere.

Acknowledgements. We kindly thank Vidya Varma, Matthias Prange, Ute Merkel, and the NCAR for providing model output used as boundary conditions for our experiments. We further thank all reviewers for their valuable comments. All simulations were produced at the Swiss National Supercomputing Centre (CSCS). We also acknowledge financial support by the Swiss National Science Foundation. 
Edited by: A. Dutton

Reviewed by: P. Bakker and two anonymous referees

\section{References}

Alexander, M. A., Bhatt, U. S., Walsh, J. E., Timlin, M. S., Miller, J. S., and Scott, J. D.: The atmospheric response to realistic Arctic sea ice anomalies in an AGCM during winter, J. Climate, 17, 890-905, 2004.

Axford, Y., Briner, J. P., Francis, D. R., Miller, G. H., Walker, I. R., and Wolfe, A. P.: Chironomids record terrestrial temperature changes throughout Arctic interglacials of the past 200,000 yr, Geol. Soc. Am. Bull., 123, 1275-1287, doi:10.1130/B30329.1, 2011.

Bakker, P., Stone, E. J., Charbit, S., Gröger, M., Krebs-Kanzow, U., Ritz, S. P., Varma, V., Khon, V., Lunt, D. J., Mikolajewicz, U., Prange, M., Renssen, H., Schneider, B., and Schulz, M.: Last interglacial temperature evolution - a model inter-comparison, Clim. Past, 9, 605-619, doi:10.5194/cp-9-605-2013, 2013.

Bauch, H. A., Kandiano, E. S., and Helmke, J. P.: Contrasting ocean changes between the subpolar and polar North Atlantic during the past $135 \mathrm{ka}$, Geophys. Res. Lett., 39, L11604, doi:10.1029/2012GL051800, 2012.

Berger, A. L.: Long-term variations of daily insolation and Quaternary climatic changes, J. Atmos. Sci., 35, 2362-2367, 1978.

Born, A. and Stocker, T. F.: Two Stable Equilibria of the Atlantic Subpolar Gyre, J. Phys. Oceanogr., 44, 246-264, doi:10.1175/JPO-D-13-073.1, 2014.

Born, A., Nisancioglu, K. H., and Braconnot, P.: Sea ice induced changes in ocean circulation during the Eemian, Clim. Dynam., 35, 1361-1371, doi:10.1007/s00382-009-0709-2, 2010.

Born, A., Nisancioglu, K. H., and Risebrobakken, B.: Late Eemian warming in the Nordic Seas as seen in proxy data and climate models, Paleoceanography, 26, PA2207, doi:10.1029/2010PA002027, 2011.

CAPE Last Interglacial Project Members: Last Interglacial Arctic warmth confirms polar amplification of climate change, Quaternary Sci. Rev., 25, 1383-1400, doi:10.1016/j.quascirev.2006.01.033, 2006.

Capron, E., Govin, A., Stone, E. J., Masson-Delmotte, V., Mulitza, S., Otto-Bliesner, B., Rasmussen, T. L., Sime, L. C., Waelbroeck, C., and Wolff, E. W.: Temporal and spatial structure of multi-millennial temperature changes at high latitudes during the Last Interglacial, Quaternary Sci. Rev., 103, 116-133, doi:10.1016/j.quascirev.2014.08.018, 2014.

Church, J., Clark, P., Cazenave, A., Gregory, J., Jevrejeva, S., Levermann, A., Merrifield, M., Milne, G., Nerem, R., and Nunn, P.: Sea level change in Climate Change 2013: The Physical Science Basis, Contribution of Working Group I to the Fifth Assessment Report of the Intergovernmental Panel on Climate Change, 1137-1216, 2013.

Collins, W. D., Bitz, C. M., Blackmon, M. L., Bonan, G. B., Bretherton, C. S., Carton, J. A., Chang, P., Doney, S. C., Hack, J. J., Henderson, T. B., Kiehl, J. T., Large, W. G., McKenna, D. S., Santer, B. D., and Smith, R. D.: The Community Climate System Model Version 3 (CCSM3), J. Climate, 19, 2122-2143, doi:10.1175/JCLI3761.1, 2006.
Deser, C., Tomas, R., Alexander, M., and Lawrence, D.: The seasonal atmospheric response to projected Arctic sea ice loss in the late twenty-first century, J. Climate, 23, 333-351, doi:10.1175/2009JCLI3053.1, 2010.

Evans, K. J., Lauritzen, P. H., Mishra, S. K., Neale, R. B., Taylor, M. A., and Tribbia, J. J.: AMIP simulation with the CAM4 spectral element dynamical core, J. Climate, 26, 689709, doi:10.1175/JCLI-D-11-00448.1, 2013.

Funder, S., Hjort, C., Landvik, J. Y., Nam, S.-I., Reeh, N., and Stein, R.: History of a stable ice margin - East Greenland during the middle and upper Pleistocene, Quaternary Sci. Rev., 17, 77-123, doi:10.1016/S0277-3791(97)00082-6, 1998.

Gent, P. R., Danabasoglu, G., Donner, L. J., Holland, M. M., Hunke, E. C., Jayne, S. R., Lawrence, D. M., Neale, R. B., Rasch, P. J., Vertenstein, M., Worley, P. H., Yang, Z. L., and Zhang, M. H.: The Community Climate System Model Version 4, J. Climate, 24, 4973-4991, doi:10.1175/2011JCLI4083.1, 2011.

Govin, A., Varma, V., and Prange, M.: Astronomically forced variations in western African rainfall $\left(21^{\circ} \mathrm{N}-20^{\circ} \mathrm{S}\right)$ during the Last Interglacial period, Geophys. Res. Lett., 41, 2117-2125, doi:10.1002/2013GL058999, 2014.

Higgins, M. E. and Cassano, J. J.: Impacts of reduced sea ice on winter Arctic atmospheric circulation, precipitation, and temperature, J. Geophys. Res.-Atmos., 114, D16107, doi:10.1029/2009JD011884, 2009.

Hobbs, W. H.: The Greenland Glacial Anticyclone, J. Meteorol., 2, 143-153, 1945.

Holton, J.: An Introduction to Dynamic Meteorology, Elsevier Science, 2004.

Hutterli, M. A., Raible, C. C., and Stocker, T. F.: Reconstructing climate variability from Greenland ice sheet accumulation: An ERA40 study, Geophys. Res. Lett., 32, L024745, doi:10.1029/2005GL024745, 2005.

Kvamstø, N. G., Skeie, P., and Stephenson, D. B.: Impact of Labrador sea-ice extent on the North Atlantic Oscillation, Int. J. Climatol., 24, 603-612, doi:10.1002/joc.1015, 2004.

Langehaug, H. R., Geyer, F., Smedsrud, L. H., and Gao, Y.: Arctic sea ice decline and ice export in the CMIP5 historical simulations, Ocean Model., 71, 114-126, doi:10.1016/j.ocemod.2012.12.006, 2013.

Large, W. G. and Danabasoglu, G.: Attribution and Impacts of Upper-Ocean Biases in CCSM3, J. Climate, 19, 2325-2346, doi:10.1175/JCLI3740.1, 2006.

Lehner, F., Born, A., Raible, C. C., and Stocker, T. F.: Amplified inception of European Little Ice Age by sea ice-ocean-atmosphere feedbacks, J. Climate, 26, 7586-7602, doi:10.1175/JCLI-D-12$00690.1,2013$.

Li, C., Battisti, D. S., Schrag, D. P., and Tziperman, E.: Abrupt climate shifts in Greenland due to displacements of the sea ice edge, Geophys. Res. Lett., 32, L19702, doi:10.1029/2005GL023492, 2005.

Li, C., Battisti, D. S., and Bitz, C. M.: Can North Atlantic Sea Ice Anomalies Account for Dansgaard-Oeschger Climate Signals?, J. Climate, 23, 5457-5475, doi:10.1175/2010JCLI3409.1, 2010.

Lunt, D. J., Abe-Ouchi, A., Bakker, P., Berger, A., Braconnot, P., Charbit, S., Fischer, N., Herold, N., Jungclaus, J. H., Khon, V. C., Krebs-Kanzow, U., Langebroek, P. M., Lohmann, G., Nisancioglu, K. H., Otto-Bliesner, B. L., Park, W., Pfeiffer, M., Phipps, S. J., Prange, M., Rachmayani, R., Renssen, H., Rosenbloom, N., 
Schneider, B., Stone, E. J., Takahashi, K., Wei, W., Yin, Q., and Zhang, Z. S.: A multi-model assessment of last interglacial temperatures, Clim. Past, 9, 699-717, doi:10.5194/cp-9-699-2013, 2013.

Merkel, U., Prange, M., and Schulz, M.: ENSO variability and teleconnections during glacial climates, Quaternary Sci. Rev., 29, 86-100, doi:10.1016/j.quascirev.2009.11.006, 2010.

Merz, N., Raible, C. C., Fischer, H., Varma, V., Prange, M., and Stocker, T. F.: Greenland accumulation and its connection to the large-scale atmospheric circulation in ERA-Interim and paleoclimate simulations, Clim. Past, 9, 2433-2450, doi:10.5194/cp9-2433-2013, 2013.

Merz, N., Born, A., Raible, C. C., Fischer, H., and Stocker, T. F.: Dependence of Eemian Greenland temperature reconstructions on the ice sheet topography, Clim. Past, 10, 1221-1238, doi:10.5194/cp-10-1221-2014, 2014a.

Merz, N., Gfeller, G., Born, A., Raible, C. C., Stocker, T. F., and Fischer, H.: Influence of ice sheet topography on Greenland precipitation during the Eemian interglacial, J. Geophys. Res.-Atmos., 119, 10749-10768, doi:10.1002/2014JD021940, 2014b.

Neale, R. B., Richter, J. H., Conley, A. J., Park, S., Lauritzen, P. H., Gettelman, A., Rasch, P. J., Vavrus, J., S., Taylor, M. A., C., Zhang, M., and Lin, S.: Description of the NCAR Community Atmosphere Model (CAM4), National Center for Atmospheric Research Tech. Rep. NCAR/TN+STR, 194 pp., 2010.

NEEM community members: Eemian interglacial reconstructed from a Greenland folded ice core, Nature, 493, 489-494, doi:10.1038/nature11789, 2013.

Nikolova, I., Yin, Q., Berger, A., Singh, U. K., and Karami, M. P.: The last interglacial (Eemian) climate simulated by LOVECLIM and CCSM3, Clim. Past, 9, 1789-1806, doi:10.5194/cp-9-17892013, 2013.

Oleson, K., Lawrence, D., Bonan, G., Flanner, M., Kluzek, E., Lawrence, P., Levis, S., Swenson, S., Thornton, P., Dai, A., Decker, M., Dickinson, R., Feddema, J., Heald, C., Hoffman, J.F., Mahowald, N., Niu, G.-Y., Qian, T., Randerson, J., Running, S., Sakaguchi, K., Slater, A., Stockli, R., Wang, A., Yang, Z.-L., Zeng, X., and Zeng, X.: Technical description of version 4.0 of the Community Land Model (CLM), National Center for Atmospheric Research Technical Note NCAR/TN-478+STR, 257 pp., doi:10.5065/D6FB50WZ, 2010.

Otto-Bliesner, B. L., Rosenbloom, N., Stone, E. J., McKay, N. P., Lunt, D. J., Brady, E. C., and Overpeck, J. T.: How warm was the last interglacial? New model-data comparisons, Philos. T. R. Soc. Lond., 371, 20130097, doi:10.1098/rsta.2013.0097, 2013.

Pausata, F. S. and Loefverstroem, M.: On the enigmatic similarity in Greenland $\delta^{18} \mathrm{O}$ between the Oldest and Younger Dryas, Geophys. Res. Lett., 42, 10470-10477, doi:10.1002/2015GL066042, 2015.

Petoukhov, V. and Semenov, V. A.: A link between reduced Barents-Kara sea ice and cold winter extremes over northern continents, J. Geophys. Res.-Atmos., 115, D21111, doi:10.1029/2009JD013568, 2010.

Petrie, R. E., Shaffrey, L. C., and Sutton, R. T.: Atmospheric Impact of Arctic Sea Ice Loss in a Coupled Ocean-Atmosphere Simulation, J. Climate, 28, 9606-9622, doi:10.1175/JCLI-D-15-0316.1, 2015.

Raible, C. and Blender, R.: Northern Hemisphere midlatitude cyclone variability in GCM simulations with dif- ferent ocean representations, Clim. Dynam., 22, 239-248, doi:10.1029/2009JD013568, 2004.

Rinke, A., Dethloff, K., Dorn, W., Handorf, D., and Moore, J.: Simulated Arctic atmospheric feedbacks associated with late summer sea ice anomalies, J. Geophys. Res.-Atmos., 118, 7698-7714, doi:10.1002/jgrd.50584, 2013.

Screen, J. A. and Simmonds, I.: Increasing fall-winter energy loss from the Arctic Ocean and its role in Arctic temperature amplification, Geophys. Res. Lett., 37, L16707, doi:10.1029/2010GL044136, 2010.

Screen, J. A., Simmonds, I., Deser, C., and Tomas, R.: The atmospheric response to three decades of observed Arctic sea ice loss, J. Climate, 26, 1230-1248, doi:10.1175/JCLI-D-12$00063.1,2013$

Sime, L. C., Risi, C., Tindall, J. C., Sjolte, J., Wolff, E. W., Masson-Delmotte, V., and Capron, E.: Warm climate isotopic simulations: what do we learn about interglacial signals in Greenland ice cores?, Quaternary Sci. Rev., 67, 59-80, doi:10.1016/j.quascirev.2013.01.009, 2013.

Sjolte, J., Hoffman, G., and Johnsen, S. J.: Modelling the response of stable water isotopes in Greenland precipitation to orbital configurations of the previous interglacial, Tellus B, 66, 22872, doi:10.3402/tellusb.v66.22872, 2014.

Smith, L., Miller, G. H., Otto-Bliesner, B., and Shin, S.-I.: Sensitivity of the Northern Hemisphere climate system to extreme changes in Holocene Arctic sea ice, Quaternary Sci. Revi., 22, 645-658, doi:10.1016/S0277-3791(02)00166-X, 2003.

Tsukernik, M., Kindig, D. N., and Serreze, M. C.: Characteristics of winter cyclone activity in the northern North Atlantic: Insights from observations and regional modeling, J. Geophys. Res.-Atmos., 112, D03101, doi:10.1029/2006JD007184, 2007.

Turney, C. S. and Jones, R. T.: Does the Agulhas Current amplify global temperatures during super-interglacials?, J. Quaternary Sci., 25, 839-843, doi:10.1002/jqs.1423, 2010.

Van Nieuwenhove, N., Bauch, A., Eynaud, F., Kandiano, E., Cortijo, E., and Turon, J.-L.: Evidence for delayed poleward expansion of North Atlantic surface waters during the last interglacial (MIS 5e), Quaternary Sci. Rev., 30, 934-946, doi:10.1016/j.quascirev.2011.01.013, 2011.

Varma, V., Prange, M., and Schulz, M.: Transient simulations of the present and the last interglacial climate using a coupled general circulation model: effects of orbital acceleration, Geosci. Model Dev. Discuss., 8, 5619-5641, doi:10.5194/gmdd-8-5619-2015, 2015.

Vizcaino, M., Lipscomb, W. H., Sacks, W. J., van Angelen, J. H., Wouters, B., and van den Broeke, M. R.: Greenland Surface Mass Balance as Simulated by the Community Earth System Model. Part I: Model Evaluation and 1850-2005 Results, J. Climate, 26, 7793-7812, doi:10.1175/JCLI-D-12-00615.1, 2013.

Yeager, S. G., Shields, C. A., Large, W. G., and Hack, J. J.: The low-resolution CCSM3, J. Climate, 19, 2545-2566, doi:10.1175/JCLI3744.1, 2006.

Zhang, X., Prange, M., Merkel, U., and Schulz, M.: Instability of the Atlantic overturning circulation during Marine Isotope Stage 3, Geophys. Res. Lett., 41, 4285-4293, doi:10.1002/2014GL060321, 2014. 